\title{
RESPONSABILIDAD DEL VICEPRESIDENTE DE LA REPÚBLICA EN EJERCICIO DE SUS FUNCIONES CONSTITUCIONALES ${ }^{1}$
}

\author{
Paula Ximena Muñoz Márquez ${ }^{2}$ \\ Universidad Santo Tomás-Bogotá
}

Fecha de recepción: 30.04.2014

Fecha de evaluación: 30.05.2014

\section{RESUMEN}

Fecha de aprobación: 15.07.2014

El presente artículo pretende analizar la figura de la Vicepresidencia desde el punto de vista del ejercicio de las funciones constitucionales asignadas por la Constitución política de 1991, artículo 202 inciso $3^{\circ}$ y $5^{\circ}$. A partir de una metodología cualitativa con enfoque histórico hermenéutico, El objetivo principal será determinar la responsabilidad del Vicepresidente de la República en el ordenamiento jurídico colombiano en la Constitución de 1991, partiendo de la identificación de los antecedentes constitucionales de la figura de la Vicepresidencia, la posición jurídica del Vicepresidente de la República como funcionario público en ejercicio de las funciones propias de su cargo, para finalmente determinar la responsabilidad del Vicepresidente en caso de contravenir la Constitución o las leyes.

\section{PALABRAS CLAVES}

Vicepresidente de la República, Vicepresidencia de la República, responsabilidad, funcionario público, sui generis.

\section{ABSTRACT}

This article aims to analyze the figure of the Vice President from the point of view of the exercise of the constitutional functions assigned by the policy of 1991 Constitution, Article 202 paragraph 3 and 5th. From a qualitative methodology with historical hermeneutic approach, the main objective will be to determine the responsibility of the Vice President in the Colombian legal system in the Constitution of 1991, from the identification of the constitutional history of the figure of the Vice President, the legal position of the Vice President as a public official exercising the functions of his office, to finally determine the responsibility of the Vice President should contravene the Constitution or the laws.

\section{KEY WORDS}

Vice president, public official.

\footnotetext{
${ }^{1}$ Este artículo es producto de la tesis de Maestría en Derecho Público dirigida por Ricardo Palomares de la Universidad Santo Tomás de Bogotá.

${ }^{2}$ Abogada de la Universidad de Manizales y magister en Derecho Público de la Universidad Santo Tomás. La autora agradece los comentarios y sugerencias al profesor y tutor Ricardo Palomares. Este artículo es responsabilidad exclusiva de la autora. Contacto: anemixm@hotmail.com
} 


\section{Introducción}

La figura de la Vicepresidencia, de origen norteamericano y adoptada en el ordenamiento jurídico colombiano desde 1819, ha sido protagonista en diferentes momentos históricos. Después de su abolición en 1905, la Vicepresidencia de la República fue incluida nuevamente en el art. 202 de la Constitución Política de Colombia de 1991 (en adelante ConstPol), consagrando que:

"El Vicepresidente de la República será elegido por votación popular el mismo día y en la misma fórmula con el Presidente de la República.

Los candidatos para la segunda votación, si la hubiere, deberán ser en cada fórmula quienes la integraron en la primera.

El Vicepresidente tendrá el mismo período del Presidente y lo reemplazará en sus faltas temporales o absolutas, aun en el caso de que éstas se presenten antes de su posesión.

En las faltas temporales del Presidente de la República bastará con que el Vicepresidente tome posesión del cargo en la primera oportunidad, para que pueda ejercerlo cuantas veces fuere necesario. En caso de falta absoluta del Presidente de la República, el Vicepresidente asumirá el cargo hasta el final del período.

El Presidente de la República podrá confiar al Vicepresidente misiones o encargos especiales $y$ designarlo en cualquier cargo de la rama ejecutiva. El Vicepresidente no podrá asumir funciones de Ministro Delegatario".

Esta norma constitucional ha abierto la discusión acerca de las funciones asignadas al Vicepresidente de la República, tomando en cuenta no solo los altos costos que acarrea el sostenimiento del cargo para el país, sino también el ejercicio de tales funciones.

En consideración a lo anterior, se analizará en el presente artículo si el Vicepresidente de la República es sujeto de responsabilidad en el ordenamiento jurídico colombiano a partir de la Constitución Política de 1991, teniendo en cuenta que a la luz del art. 202 inc. $3^{\circ}$ y $5^{\circ}$ de la ConstPol, el Vicepresidente de la República pueda ser considerado como una figura sui generis por cuanto no tiene funciones específicas propias del cargo, y solo puede ser sujeto responsable en la medida en 
MUÑOZ M., PAULA XIMENA (2014): “RESPONSABILIDAD DEL VICEPRESIDENTE DE LA REPÚBLICA EN EJERCICIO DE SUS FUNCIONES CONSTITUCIONALES”, VIA INVENIENDI ET IUDICANDI, Vol. 9, No. 1, pp.

que remplace al presidente de la República, evento en el cual, será juzgado como presidente y no como Vicepresidente.

Es necesario, sin embargo, hacer una precisión. El objeto central del artículo no es el análisis de la responsabilidad del Estado por actuaciones del Vicepresidente de la República, es decir, no se analizará cuál podría ser el título de imputación de responsabilidad estatal por actuación de uno de sus funcionarios. Asimismo, es necesario aclarar que el presente trabajo tampoco constituye un análisis o abstracción respecto a las teorías del servicio público pues, si bien se revisa si el Vicepresidente de la República es funcionario público o no, no se trabaja una sistematización del concepto enunciado. La importancia radica, en realidad, en establecer si existe un agente estatal carente de funciones, constituyéndose una excepción tácita a la regla de servidor con funciones concretas, y, por tanto, un agente carente de responsabilidad. Esto implica, entonces, un cuestionamiento directo a la posición de un Vicepresidente con una simple función de "vocación sucesoral", así como la simple figura sui generis, enunciada anteriormente.

La metodología utilizada en la investigación es de corte cualitativo con enfoque histórico - hermenéutico, la cual permitirá dilucidar si efectivamente el Vicepresidente es sujeto responsable por el ejercicio de sus funciones constitucionales, partiendo de la interpretación histórica desde el origen de la figura de la Vicepresidencia en Estados Unidos, y a su vez, interpretarla en concordancia con el ordenamiento jurídico colombiano en las distintas constituciones, analizando la manera como fueron concebidas las funciones asignadas al Vicepresidente; asimismo, la responsabilidad en caso de contravención de la Constitución o las leyes al momento de la comisión de la falta.

Cabe aclarar que el desarrollo y análisis del problema jurídico planteado se hará desde el contexto histórico y jurídico colombiano y no desde el punto de vista del derecho comparado, ya que a pesar de tener un enfoque internacionalista, se pretende determinar si el Vicepresidente de la República es responsable por el ejercicio de las funciones asignadas por la Constitución colombiana de 1991, y no realizar una comparación o analogía de los distintos ordenamientos jurídicos sea en Europa o América Latina para dilucidar el problema jurídico planteado. Además de REVISTA VIA INVENIENDI ET IUDICANDI, Vol. 9, No. 1 UNIVERSIDAD SANTO TOMÁS, BOGOTÁ 
MUÑOZ M., PAULA XIMENA (2014): “RESPONSABILIDAD DEL VICEPRESIDENTE DE LA REPÚBLICA EN EJERCICIO DE SUS FUNCIONES CONSTITUCIONALES”, VIA INVENIENDI ET IUDICANDI, Vol. 9, No. 1, pp.

ello, el estudio de un tema de investigación tiene unas clasificaciones metodológicas que exceden el cuerpo mismo de la investigación.

Para lograr el objetivo mencionado anteriormente, el artículo se dividirá en cuatro partes. En primer lugar, se realizará una contextualización fáctica analizando el origen de la Vicepresidencia, inicialmente creada en Estados Unidos, y la adopción de la figura en el ordenamiento jurídico colombiano, pasando por las diferentes constituciones en las cuales hizo parte y aquellas en que fue abolida. En una segunda parte, se analizará la figura de la Vicepresidencia de la República a partir de la Constitución Política de Colombia de 1991, y a la consideración del Vicepresidente como funcionario público, desde el punto de vista doctrinal y jurisprudencial. En tercer lugar, está dedicado al estudio de la responsabilidad del Vicepresidente de la República tomando en cuenta las funciones constitucionales asignadas. Por último, conclusiones finales.

\section{La Vicepresidencia de la República}

La Vicepresidencia de la República quedó consagrada en la ConstPol en el art. 202 y siguientes del Cap. 3:

"El Vicepresidente de la República será elegido por votación popular el mismo día y en la misma fórmula con el Presidente de la República (...). El Vicepresidente tendrá el mismo período del Presidente y lo reemplazará en sus faltas temporales o absolutas, aun en el caso de que éstas se presenten antes de su posesión. En las faltas temporales del Presidente de la República bastará con que el Vicepresidente tome posesión del cargo en la primera oportunidad, para que pueda ejercerlo cuantas veces fuere necesario. En caso de falta absoluta del Presidente de la República, el Vicepresidente asumirá el cargo hasta el final del período. El Presidente de la República podrá confiar al Vicepresidente misiones o encargos especiales $y$ designarlo en cualquier cargo de la rama ejecutiva. El Vicepresidente no podrá asumir funciones de Ministro Delegatario". 
MUÑOZ M., PAULA XIMENA (2014): “RESPONSABILIDAD DEL VICEPRESIDENTE DE LA REPÚBLICA EN EJERCICIO DE SUS FUNCIONES CONSTITUCIONALES”, VIA INVENIENDI ET IUDICANDI, Vol. 9, No. 1, pp.

De acuerdo al art. 202 inc. $3^{\circ}$ ConstPol, la primera función asignada al Vicepresidente de la República es el remplazo del Presidente en caso de faltas temporales o absolutas. Por faltas temporales se entiende, conforme al art. 194 inc. $2^{\circ}$ en concordancia con el art. 193 de la ConstPol, la licencia y la enfermedad del Presidente, y la suspensión en el ejercicio del cargo decretada por el Senado, previa admisión pública de la acusación, según el numeral $1^{\circ}$ del art. 175 de la ConstPol. Por faltas absolutas se entiende conforme al art. 194 inc. $1^{\circ}$ ConstPol, la muerte del Presidente, su renuncia aceptada, la destitución decretada por sentencia, la incapacidad física permanente y el abandono del cargo, declarados éstos dos últimos por el Senado. Junto con la función de remplazo del Presidente, la ConstPol ha consagrado una cláusula abierta de funciones para el Vicepresidente de la República. Así, el art. 202 inc. $5^{\circ}$ ConstPol establece que el Presidente de la República podrá confiar al Vicepresidente misiones o encargos especiales y designarlo en cualquier cargo de la rama ejecutiva. Esta cláusula abierta de funciones ha sido objeto de discusiones doctrinales, pues la misma no es del todo clara. Por un lado, podría sostenerse que el Vicepresidente sólo tiene una función concreta, a saber, el remplazo al Presidente de la República. Por otra parte, podría decirse que la función del Vicepresidente, es cumplir con encargos no determinados por la ConstPol, a discreción del mandatario de turno. DE LA CALLE (2011: 37) ha sostenido que la Vicepresidencia realmente no ha logrado acomodarse suficientemente en Colombia, por no tener función distinta a la encomendada por el presidente, dejando un cierto vacío e incertidumbre. Según el autor, "la Vicepresidencia nace del deseo de la Constituyente de que nadie desempeñara la presidencia sin estar respaldado y legitimado por el voto popular. Por eso se eliminó la antigua figura nombrada por el Congreso de la República, y se prefirió este sistema de tiquete, donde se vota por Presidente y Vicepresidente (...)". En contraposición a lo expuesto por DE LA CALLE, para CORREDOR (2007: 101) la adopción de la figura de la Vicepresidencia en 1991, resolvió a través del artículo 202 de la ConstPol, el vacío que existió en la Constitución anterior -la de 1886-, respecto de la persona que reemplazaría en caso de muerte al presidente.

En virtud del análisis de la contextualización fáctica del Vicepresidente de la República desde su adopción en la ConstPol, no ha sido posible esclarecer el límite para el desempeño de las funciones constitucionales asignadas; y como REVISTA VIA INVENIENDI ET IUDICANDI, Vol. 9, No. 1 UNIVERSIDAD SANTO TOMÁS, BOGOTÁ 
MUÑOZ M., PAULA XIMENA (2014): “RESPONSABILIDAD DEL VICEPRESIDENTE DE LA REPÚBLICA EN EJERCICIO DE SUS FUNCIONES CONSTITUCIONALES”, VIA INVENIENDI ET IUDICANDI, Vol. 9, No. 1, pp.

consecuencia de ello, tampoco es posible identificar a simple vista cómo y cuándo es responsable el Vicepresidente por el ejercicio de sus funciones como Vicepresidente; distinta a la responsabilidad cuando se encuentre al mando del ejecutivo o en desempeño de algún cargo de la rama ejecutiva. Ello, en contraposición con los arts. $4^{\circ}$ y $6^{\circ}$ ConstPol al consagrar que todos los servidores públicos y en general todas las personas residentes en Colombia, sean estos nacionales o extranjeros, son responsables por sus actos u omisiones por violación a la Constitución o la ley. En efecto, es necesario determinar si el Vicepresidente de la República es un funcionario público teniendo en cuenta que la Constitución Nacional prohíbe la existencia de un empleo público sin funciones detalladas en la ley o reglamento; para ello resulta indispensable conocer la historia de la figura de la Vicepresidencia y su adopción en el ordenamiento jurídico colombiano.

\section{A. Historia de la Vicepresidencia}

La Vicepresidencia fue creada en la Convención Constitucional de 1787 En Estados Unidos. Aunque ningún delegado apoyó con ímpetu la creación de la Vicepresidencia, esta generó enormes controversias. (GARVEY, 2008). Por ejemplo, el senador Elbridge Gerry, delegado de Massachusetts, consideró que existía una enorme influencia del presidente sobre el control del Vicepresidente en el Senado, y en razón a ello, generaría un impacto en la doctrina de separación de poderes. Para George Mason, de Virginia, sentó su posición en contra de la creación de la figura Vicepresidencial, ya que consideraba una mixtura de roles entre el poder legislativo y el poder ejecutivo; y la intromisión por parte del Vicepresidente sobre el poder legislativo en el Senado. (GARVEY, 2008). Por otro lado, Roger Sherman de Connecticut, recordó a los delegados que si el Vicepresidente no tuviera el lugar en la presidencia del Senado, él estaría sin empleo, ya que no fueron asignadas funciones en el ejecutivo. (GARVEY, 2008). Para GOLDSTEIN (1982), la creación de la Vicepresidencia en la Convención Constitucional fue una idea tardía, incluso un accidente.

Inicialmente, los 11 miembros de la Convención Constitucional concibieron la Vicepresidencia como un cargo legislativo (GOLDSTEIN 1982). Posteriormente, analizaron la figura no como un permanente heredero del presidente cuando este no 
MUÑOZ M., PAULA XIMENA (2014): “RESPONSABILIDAD DEL VICEPRESIDENTE DE LA REPÚBLICA EN EJERCICIO DE SUS FUNCIONES CONSTITUCIONALES”, VIA INVENIENDI ET IUDICANDI, Vol. 9, No. 1, pp.

pudiera asumir o seguir ejerciendo el cargo, sino más bien como un dispositivo para facilitar la elección del presidente (GOLDSTEIN, 2002). Fuertes lealtades regionales y estatales eran una preocupación importante en la creación de un proceso electoral que resultara fuerte, efectivo y unificador para el presidente (GARVEY, 2008). La Vicepresidencia existió principalmente, como el significado de obligar a los electores del estado, a apoyar a un candidato proveniente de otro estado. (GARVEY, 2008).

La creación de la figura Vicepresidencial no fue propuesta hasta el 4 de septiembre de 1787; el borrador final de la Constitución fue aprobado justo 13 días después. (GOLDSTEIN 1982).

Finalmente, en la Constitución Federal de 1787 de Estados Unidos, la disposición constitucional relativa a las funciones del Vicepresidente quedó consagrada en el artículo I, Sección III: "El Vicepresidente de los Estados Unidos será Presidente del Senado, pero no tendrá voto excepto en caso de empate”; y en el artículo II, Sección I: "en caso de remoción del presidente de la oficina, su muerte, renuncia o incapacidad para desempeñar los poderes o deberes del referido cargo, este pasará al Vicepresidente y el Congreso podrá proveer mediante una ley el caso de destitución, muerte, renuncia o incapacidad, tanto del Presidente y el Vicepresidente, declarar qué funcionario fungirá como Presidente, Director de dicho actuar en consecuencia, hasta que la incapacidad cese o un Presidente sea elegido" (Constitution of the United States of America. Artículo I, Sección III. Marzo 4 de 1787)

Además de las funciones consagradas en el artículo II, sección I de la Constitución Federal, la enmienda 25 de la Constitución, ratificada el 10 de febrero de 1967 (Aditional amendements to the Unites States Constitution. Enmienda 25. 10 de febrero de 1967), consagró la prerrogativa al Vicepresidente de poder decidir en caso de ser cuestionada la capacidad de gobernar del presidente (BRITO, s.f.),:

\footnotetext{
...Sección 3.

Siempre que el Presidente comunique al Presidente pro témpore del Senado y al "Speaker" de la Cámara de Representantes su declaración por escrito de que se encuentra incapacitado para desempeñar los
} 
MUÑOZ M., PAULA XIMENA (2014): “RESPONSABILIDAD DEL VICEPRESIDENTE DE LA REPÚBLICA EN EJERCICIO DE SUS FUNCIONES CONSTITUCIONALES”, VIA INVENIENDI ET IUDICANDI, Vol. 9, No. 1, pp.

poderes y deberes de su cargo, y hasta que les comunique una declaración por escrito en contrario, dichos poderes y deberes serán desempeñados por el Vicepresidente como Presidente en funciones.

\section{Sección 4.}

Siempre que el Vicepresidente y una mayoría de los jefes de los departamentos ejecutivos o cualquier otro cuerpo que el Congreso disponga por ley, comunique al Presidente pro témpore del Senado y al "Speaker" de la Cámara de Representantes su declaración por escrito de que el Presidente se encuentra incapacitado para desempeñar los poderes y deberes de su cargo, el Vicepresidente asumirá inmediatamente los poderes y deberes del cargo como Presidente en funciones.

Posteriormente, cuando el Presidente comunique al Presidente pro témpore del Senado y al "Speaker" de la Cámara de Representantes su declaración por escrito de que no existe la incapacidad, reasumirá los poderes y deberes de su cargo a menos que el Vicepresidente y una mayoría de los jefes de los departamentos ejecutivos o de cualquier otro cuerpo que el Congreso disponga por ley, comunique dentro de cuatro días al Presidente pro témpore del Senado y al "Speaker" de la Cámara de Representantes su declaración por escrito de que el Presidente está incapacitado para desempeñar los poderes y deberes de su cargo. Inmediatamente el Congreso decidirá la cuestión, reuniéndose dentro de las cuarenta y ocho horas si no estuviere en sesión. Si el Congreso, dentro de los veintiún días siguientes al recibo de la última declaración por escrito, o, si el Congreso no estuviere en sesión, dentro de los veintiún días siguientes a la convocatoria al Congreso para que se reúna, determina por un voto de las dos terceras partes de ambas Cámaras que el Presidente está incapacitado para desempeñar los poderes y deberes de su cargo, el Vicepresidente continuará desempeñando el mismo como Presidente en funciones; de lo contrario, el Presidente reasumirá los poderes y deberes de su cargo. (Constitution of the United States of America. Artículo I, Sección III. Marzo 4 de 1787)

Las funciones del Vicepresidente consagradas en la Constitución Federal, generaron en la doctrina diferentes cuestionamientos acerca de qué es lo que debe pasar al Vicepresidente cuando el presidente se encuentre inmerso en alguna falta temporal o absoluta (PRITCHETT, 1965); si el Vicepresidente se convierte en 
MUÑOZ M., PAULA XIMENA (2014): “RESPONSABILIDAD DEL VICEPRESIDENTE DE LA REPÚBLICA EN EJERCICIO DE SUS FUNCIONES CONSTITUCIONALES”, VIA INVENIENDI ET IUDICANDI, Vol. 9, No. 1, pp.

presidente, o simplemente "actúa" como tal hasta que se elija un nuevo presidente (PRITCHETT, 1965). Estos interrogantes fueron resueltos por la Enmienda 25 de la Constitución Federal, al establecer que en caso de incapacidad del presidente para ejercer su cargo, entra a sustituirlo el Vicepresidente; incluso cuenta con la enorme potestad de decidir y una mayoría de los jefes de departamento del estado sobre la capacidad del presidente para reasumir nuevamente el cargo (Constitution of the United States of America. Artículo I, Sección III. Marzo 4 de 1787)

En consecuencia, con la creación de la Vicepresidencia, los padres fundadores de la Constitución de 1787 quisieron garantizar un ejecutivo permanente, previendo al lado del presidente, una institución que estuviera disponible para sustituir al jefe de Estado en caso de muerte, renuncia o impedimento permanente del primer mandatario, y pudiera asumir el cargo. (ALARCÓN, 1999)

No obstante, a los miembros creadores de la Convención les preocupó inicialmente la función del Vicepresidente de ser el presidente del Senado, porque cabía la posibilidad de que pudiera presidir su propio juicio político (GARVEY, 2008); en razón a ello, reconociendo un posible conflicto de intereses en caso de ser sometido el presidente a un juicio político, fue añadida a la Constitución Federal de 1787, una cláusula con el art. I., Sección 3, en la cual se nombra al Magistrado Presidente de la Corte Suprema de Justicia, como competente para presidir un juicio político presidencial. (GARVEY, 2008): “...Tan solo el Senado podrá conocer de procedimientos de juicios políticos. Cuando se reúna para este fin, los senadores prestarán juramento o harán promesa de cumplir fielmente su cometido. Cuando el Presidente de los Estados Unidos esté aprobado, el Presidente del Tribunal Supremo presidirá: Y a ninguna persona se le condenará sino ocurre el voto de dos tercios de los miembros presentes. La sentencia en los casos de acusación no se extenderá más allá de la destitución del Cargo y la inhabilitación para ocupar y disfrutar cualquier empleo honorífico, de confianza o remunerado, de los Estados Unidos, pero el individuo condenado, no obstante, quedará expuesto y sujeto a acusación, juicio, sentencia y castigo con arreglo a la ley" (Constitution of the United States of America. Artículo I, Sección III. Marzo 4 de 1787) 
MUÑOZ M., PAULA XIMENA (2014): “RESPONSABILIDAD DEL VICEPRESIDENTE DE LA REPÚBLICA EN EJERCICIO DE SUS FUNCIONES CONSTITUCIONALES”, VIA INVENIENDI ET IUDICANDI, Vol. 9, No. 1, pp.

En materia de responsabilidad, el Vicepresidente de Estados Unidos es separado de su cargo al ser acusado y declarado culpable por los crímenes de traición, cohecho u otros y faltas graves, según el Artículo II, Sección 4 de la Constitución Federal.

En general, la creación y adopción de la figura de la Vicepresidencia de Estados Unidos, tuvo gran influencia en América Latina, ya que por ser países con régimen presidencial, y con el ánimo de solidificar los poderes al ejecutivo (ALARCÓN, 1999), adoptaron, como el caso de Colombia, a la Vicepresidencia para reemplazar al primer mandatario cuando este faltare de manera temporal o permanente.

Desde el punto de vista del ordenamiento jurídico colombiano, la Vicepresidencia no ha sido una figura nueva en Colombia, ha tenido apariciones en diferentes constituciones como son las de 1821, 1830, 1832, 1843, 1853, 1886 y 1991, siendo la Vicepresidencia más antigua en comparación con la Designatura. (ORTIZ, 2005).

La figura del Designado aparece en la historia del constitucionalismo colombiano, en principio, en función del poder legislativo y no del ejecutivo (AGUILERA, 2005). En la Primera República Granadina de 1810-1816, cuando las provincias del Nuevo Reino de Granada declararon su autonomía e independencia, surge la figura del designado, estableciendo que en las ausencias del presidente del poder legislativo o "prefecto de la legislatura", éste sería remplazado por "un designado" elegido por los miembros del cuerpo legislativo (AGUILERA, 2005): "El Cuerpo Legislativo, para la interior economía y organización de sus sesiones, nombrará un presidente particular del Cuerpo mismo, con el título de Prefecto de la Legislatura, un Designado para sus ausencias..." Constitución de Cundinamarca. Artículo 7. 4 de abril de 1811.

Antes de la Constitución de 1821, la figura de la Vicepresidencia ya se había incorporado en el territorio nacional. El art. 4 de la Ley Fundamental de la República de Colombia de 1819, consagraba que: "El Poder Ejecutivo de la República será ejercido por un Presidente $y$, en su defecto, por un Vicepresidente, nombrados REVISTA VIA INVENIENDI ET IUDICANDI, Vol. 9, No. 1 UNIVERSIDAD SANTO TOMÁS, BOGOTÁ 
MUÑOZ M., PAULA XIMENA (2014): “RESPONSABILIDAD DEL VICEPRESIDENTE DE LA REPÚBLICA EN EJERCICIO DE SUS FUNCIONES CONSTITUCIONALES”, VIA INVENIENDI ET IUDICANDI, Vol. 9, No. 1, pp.

ambos interinamente por el actual Congreso" (Constitución de 1821 del 30 de agosto de 1821). En esta Constitución no se hizo mención específica acerca de las funciones y responsabilidades que debía asumir el Vicepresidente.

La Constitución de la Nueva Granada de 1821, consagró como función del Vicepresidente suplir al Jefe del Ejecutivo en sus faltas temporales o absolutas. Así, el art. 108 de la Constitución de 1821 estipuló que: "Habrá un Vicepresidente, que ejercerá las funciones de Presidente en caso de muerte, destitución, o renuncia, hasta que se nombre sucesor, que será en la próxima reunión de las Asambleas Electorales. También entrará en las mismas funciones por ausencia, enfermedad o cualquiera otra falta temporal del Presidente" (Constitución de 1821 del 30 de agosto de 1821). Asimismo, como el presidente tenía el mando supremo de las fuerzas de mar y tierra, exclusivamente encargado de su dirección, cuando decidía encargarse personalmente de las fuerzas de la República, el Vicepresidente debía asumir las funciones del Poder Ejecutivo, al respecto el art. 118 de la Constitución de 1821.

Un ejemplo de lo anterior puede verse cuando Simón Bolívar -primer mandatario de la época- se disponía viajar a las provincias del sur, con el fin principal de incorporar el departamento de Quito al territorio libre de Colombia, delegó a su Vicepresidente -Francisco de Paula Santander- las funciones del ejecutivo a través de decreto de 9 de octubre de 1821. (ALARCÓN, 1999)

Además de reemplazar al presidente en sus faltas temporales o absolutas, el Vicepresidente hacía parte del Consejo de Gobierno - según el art. 133 de la Constitución de 1821-, asesorando al primer mandatario junto con un Ministro de la Alta Corte de Justicia y los Secretarios del Despacho, sin que sus sugerencias u opiniones generaran obligatorio cumplimiento. (Constitución de 1821 del 30 de agosto de 1821)

Por consiguiente, las funciones del Vicepresidente constaban únicamente de reemplazar al presidente cuando éste estuviera en incapacidad de hacerlo, sea por falta absoluta o temporal. Cuando asesoraba al presidente en el Consejo de Ministros, como no generaba ninguna obligación para el presidente atender las recomendaciones, el nivel de responsabilidad del Vicepresidente en este sentido era REVISTA VIA INVENIENDI ET IUDICANDI, Vol. 9, No. 1 UNIVERSIDAD SANTO TOMÁS, BOGOTÁ 
MUÑOZ M., PAULA XIMENA (2014): “RESPONSABILIDAD DEL VICEPRESIDENTE DE LA REPÚBLICA EN EJERCICIO DE SUS FUNCIONES CONSTITUCIONALES”, VIA INVENIENDI ET IUDICANDI, Vol. 9, No. 1, pp.

nulo. En cuanto a la responsabilidad del Vicepresidente, la Cámara de Representantes tenía el derecho exclusivo de acusar ante el Senado de la República al Vicepresidente; entonces, la responsabilidad del Vicepresidente recaía cuando se encontraba reemplazando al presidente, ya que de lo contrario, estaba a la espera de la ocurrencia de una eventual incapacidad del presidente para ejercer su cargo.

Esta Constitución de corte centralista rigió hasta el 27 de agosto de 1828, fecha en que Bolívar promulgó el Decreto Orgánico de su dictadura, dejando sin vigencia la Constitución de 1821, y eliminando la Vicepresidencia, la cual fue sustituida por el presidente del Consejo de Ministros quien sería el encargado del gobierno en caso de enfermedad, ausencia o muerte del presidente del Estado. (ORTIZ, 1993). El art. $7^{\circ}$ del Decreto Orgánico dispuso: "En los casos de enfermedad, ausencia o muerte del Presidente del Estado, se encargará del gobierno de la República el Presidente del Consejo de Ministros, y su primer acto en el último caso será el de convocar la representación nacional para dentro de un término que no exceda de ciento y cincuenta días". (Constitución de 1821 del 30 de agosto de 1821)

La presencia del Vicepresidente reducía de algún modo los poderes del presidente o, por lo menos, impedía que él actuara de manera inconstitucional, generando algunas rivalidades entre los dos funcionarios (ORTIZ, 1993). El papel de Santander, quien ocupó el cargo de Vicepresidente durante ocho años, fue decisivo como Vicepresidente ya que organizó jurídicamente en compañía de sus más cercanos colegas la nueva nación; impulsó la educación, especialmente lancasteriana, y buscó quitarle a la Iglesia el monopolio sobre ella; trabajó en la organización de la administración de justicia, e hizo política de la manera más realista y eficaz. (ORTIZ, 1993) Sin embargo, estas actuaciones fueron entendidas por Bolívar como abuso del poder por parte de Santander.

Las razones de Bolívar para la eliminación de la Vicepresidencia, se debieron no solo a los enfrentamientos que tenía constantemente con Santander por sus actuaciones, sino también Bolívar buscó "templar el rigor del régimen dictatorial". (ORTIZ, 1993) 
MUÑOZ M., PAULA XIMENA (2014): “RESPONSABILIDAD DEL VICEPRESIDENTE DE LA REPÚBLICA EN EJERCICIO DE SUS FUNCIONES CONSTITUCIONALES”, VIA INVENIENDI ET IUDICANDI, Vol. 9, No. 1, pp.

El 20 de enero de 1830, se instaló el Congreso Constituyente convocado por Simón Bolívar - que el mismo llamó admirable por la calidad de los miembros y la serenidad de los debates- para ser redactado un proyecto de Constitución, la cual fue sancionada el 5 de mayo por el Vicepresidente encargado del ejecutivo - general Domingo Caicedo-, ya que el titular Joaquín Mosquera aún no se había posesionado. Se dijo que la Constitución de 1830 nació muerta, porque se pretendía que rigiera para toda la Gran Colombia cuando ella ya se encontraba disuelta (ALARCÓN, 1999).

Fue elegido Vicepresidente para ese entonces, el General Domingo Caicedo, quien se encargó del poder ejecutivo en varias ocasiones. Más tarde fue elegido y tomó posesión del cargo como Vicepresidente el General José María Obando. (BARGUIL DE DAJER: 1990)

Esta Constitución fue más conservadora y centralista, que entre otros asuntos, revivió la institución de la Vicepresidencia. (QUINTERO, 2002). Según el art. 76 consagró: "En los casos de muerte, dimisión o incapacidad física o moral del Presidente se encargará del ejercicio del Poder Ejecutivo el Vicepresidente", (Constitución de 1830 del 5 de mayo de 1830). Pero ésta no fue la única función asignada al Vicepresidente, es decir, no sólo era el encargado de reemplazar al Jefe del Ejecutivo en sus faltas, sino además debía presidir el Consejo de Estado, al respecto el art. 95 de la Constitución de 1830: "Para auxiliar al Poder Ejecutivo con sus luces en los diversos ramos de la Administración Pública, habrá un Consejo de Estado, compuesto por el Vicepresidente de la República, quien lo presidirá, de los Ministros Secretarios del Despacho, del Procurador General de la Nación, y de doce Consejeros escogidos indistintamente de cualquiera clase de ciudadanos". (Constitución de 1830 del 5 de mayo de 1830).

Dentro de sus funciones como consejero, al Vicepresidente, junto con sus demás miembros del Consejo de Estado le correspondía, de acuerdo al art. 97 ibídem, "1. Dar su dictamen para la sanción de las leyes, y en todos los negocios graves medidas generales de la Administración pública, y en todos los casos que lo exija el Jefe del Ejecutivo; 2. Preparar, discutir y formar los proyectos de ley que hayan de presentarse al Congreso en nombre del Jefe del Ejecutivo, y 3. Hacer las REVISTA VIA INVENIENDI ET IUDICANDI, Vol. 9, No. 1 UNIVERSIDAD SANTO TOMÁS, BOGOTÁ 
MUÑOZ M., PAULA XIMENA (2014): “RESPONSABILIDAD DEL VICEPRESIDENTE DE LA REPÚBLICA EN EJERCICIO DE SUS FUNCIONES CONSTITUCIONALES”, VIA INVENIENDI ET IUDICANDI, Vol. 9, No. 1, pp.

consultas en los casos que se le atribuyen por el artículo 85 e informar sobre la aptitud, mérito y circunstancias de las personas que consultare" (Constitución de 1830 del 5 de mayo de 1830). Sin embargo, el presidente no estaba obligado a seguir el dictamen del Consejo de Estado, como lo consagró el art. 98 de la Carta Política de 1830; pero sí eran responsables ante el Senado por los dictámenes dados en contra de disposiciones expresas de la Constitución o de las leyes. Como esta Constitución duró tan poco tiempo, no se produjo doctrina alguna con respecto a la responsabilidad del Vicepresidente, sin embargo, el juzgamiento por parte del Senado al Vicepresidente, previa acusación de la Cámara de Representantes, estaría enmarcado dentro del ejercicio como primer mandatario en remplazo del presidente en sus faltas ${ }^{3}$, y cuando en el ejercicio de sus funciones como Consejero atentaran sus pronunciamientos contra la Constitución o las leyes.

En 1832 se expidió una Constitución de tendencia liberal moderada y de carácter centro - liberal. Se señala como fin de la organización política evitar el despotismo y la anarquía. Entre otros asuntos se releva el predominio del ejecutivo. (QUINTERO, 2002: 120). Entre 1832 y 1843 se encargaron del ejecutivo los Vicepresidentes Domingo Caicedo, José María Obando y José Ignacio de Márquez. La Vicepresidencia de Obando fue la más importante de este período al ocupar el cargo en 1832 por ausencia de Santander, sancionó la Carta política de 1832, y puede considerarse, al lado de José Hilario López, como el restaurador del orden legal, después de la dictadura de Urdaneta. (ORTIZ, 1993)

Se mantuvo la institución de la Vicepresidencia, que según el art. 94 de la Constitución de 1832, "Habrá un Vicepresidente que ejercerá las funciones de Presidente en los casos de muerte, destitución o renuncia, hasta que se nombre sucesor que será en la próxima reunión de las asambleas electorales. También entrará a ejercer las mismas funciones, por ausencia, enfermedad, o cualquiera otra falta temporal del Presidente". El Vicepresidente, además de reemplazar al presidente, conformaba el Consejo de Gobierno junto con los secretarios de Estado, debiendo asistir con su dictamen al Presidente de todos los negocios de la administración; pero, el presidente no tenía la

\footnotetext{
${ }^{3}$ Véase art. 51 de la Constitución de 1830 
MUÑOZ M., PAULA XIMENA (2014): “RESPONSABILIDAD DEL VICEPRESIDENTE DE LA REPÚBLICA EN EJERCICIO DE SUS FUNCIONES CONSTITUCIONALES”, VIA INVENIENDI ET IUDICANDI, Vol. 9, No. 1, pp.

obligación de seguirlo o acatarlo, como lo estableció el art. 120 ibídem. (Constitución Política del Estado de Nueva Granada del 1 de marzo de 1832)

Si bien no existieron cambios significativos en lo que atañe a la Vicepresidencia, sí los hubo en cuanto a su elección. Según el art. 97 de la Constitución Política del Estado de Nueva Granada, el Vicepresidente debía ser elegido por dos años después de elegido el Presidente, evitando al igual que en la Constitución de 1830, emulaciones entre el presidente y el Vicepresidente de la República. (ORTIZ, 2005)

La Corte Suprema - de conformidad con el art. 131 de la Constitución de 1832 - dentro de sus funciones, tenía la de conocer los delitos cometidos por el Vicepresidente; sin embargo, cuando la acusación estuviera relacionada con el ejercicio de las funciones, las penas impuestas estaban a cargo del Senado -previa acusación de la cámara de representantes-, dependiendo del nivel de gravedad, eran la de suspensión del cargo, o deponer de su empleo al acusado; pero, si el Vicepresidente -en este caso- cometía un delito por fuera de la órbita de sus funciones, la competencia recaía en la Corte Suprema. (Constitución Política del Estado de Nueva Granada del 1 de marzo de 1832)

En este sentido, el Vicepresidente respondía por el ejercicio de sus funciones, es decir, cuando estuviera a cargo del Poder Ejecutivo acusado por la Cámara de Representantes; y personalmente por la comisión de delitos comunes, siendo competente la Corte Suprema.

La Constitución de 1843, de tendencia centralista y conservadora, sería el modelo de la Constitución de 1886. (QUINTERO, 2002). Esta Carta Política, conservó la elección indirecta de presidente y Vicepresidente, siendo este último el encargado de ejercer el Poder Ejecutivo en los siguientes casos, según el art. 99: "En los casos de muerte, renuncia, destitución y suspensión, o de cualquiera otra falta temporal, accidental o perpetua del Presidente, ejercerá el poder ejecutivo el Vicepresidente de la República; y cuando por iguales causas falten o no puedan ejercerlos ni el Presidente ni el Vicepresidente, lo ejercerá el individuo que para el efecto elegirá el Congreso a pluralidad absoluta de votos, con la duración que fije la REVISTA VIA INVENIENDI ET IUDICANDI, Vol. 9, No. 1 UNIVERSIDAD SANTO TOMÁS, BOGOTÁ 
MUÑOZ M., PAULA XIMENA (2014): “RESPONSABILIDAD DEL VICEPRESIDENTE DE LA REPÚBLICA EN EJERCICIO DE SUS FUNCIONES CONSTITUCIONALES”, VIA INVENIENDI ET IUDICANDI, Vol. 9, No. 1, pp.

ley, y con las demás funciones que ésta le atribuya. Cuando no pueda ejercer el Poder Ejecutivo ninguno de los tres individuos indicados, lo ejercerán los que designe la ley, en el orden que ella establezca". (Constitución de la República de la Nueva Granada del 8 de mayo de 1843)

Sancionada la Constitución de 1843, se retomó el carácter centralista del Estado, en la cual se introdujeron cambios en el poder ejecutivo el cual pasó a ser representado por el presidente, el Vicepresidente, el designado y el Consejo de Gobierno; así, el poder ejecutivo quedó reforzado frente al poder legislativo. (ORTIZ, 1993). Un aspecto importante a resaltar, es que el Vicepresidente, mientras estuviera ocupando su cargo, no podía ser perseguido ni juzgado por delitos comunes, a menos que el Senado declarara lugar a formación de causa por la comisión de un delito común; al respecto el art. 106 de la Constitución de 1843: "El Presidente y Vicepresidente de la República mientras duran en sus destinos, y el que se halle encargado del Ejecutivo mientras lo ejerza, no pueden ser perseguidos ni juzgados por delitos comunes; sino después que, a virtud de acusación interpuesta por la Cámara de Representantes, haya declarado el Senado que ha lugar a formación de causa". (Constitución de la República de la Nueva Granada del 8 de mayo de 1843)

La Cámara de Representantes, según el art. 143 de la Constitución de 1843 le correspondió la atribución de “...acusar ante el Senado al Presidente o Vicepresidente de la República o al encargado del Poder Ejecutivo, conforme al Artículo 106, por delitos comunes; para el solo efecto de que el Senado declare si hay o no lugar a formación de causa" (Constitución de la República de la Nueva Granada del 8 de mayo de 1843). Si el Senado determinaba formación de causa por la comisión de un delito común por el Vicepresidente, quedaba suspendido de su destino o cargo, puesto posteriormente a disposición de la Corte Suprema, como competente para su juzgamiento. ${ }^{4}$

\footnotetext{
${ }^{4}$ Véase art. 121 de la Constitución de la República de la Nueva Granada del 8 de mayo de 1843 
MUÑOZ M., PAULA XIMENA (2014): “RESPONSABILIDAD DEL VICEPRESIDENTE DE LA REPÚBLICA EN EJERCICIO DE SUS FUNCIONES CONSTITUCIONALES”, VIA INVENIENDI ET IUDICANDI, Vol. 9, No. 1, pp.

El Vicepresidente seguía haciendo parte del Consejo de Gobierno al igual que en la Constitución de 1832, lo cual explica que haya llamado el presidente al Vicepresidente segundo jefe de la misma nación. (ALARCÓN, 1999)

La Constitución de 1853 fue una Constitución liberal y consagró la organización centro - federada. Aunque no era definidamente liberal, sí daba mucho margen a las provincias para organizar su administración, y los distritos parroquiales o municipios, pudieron aprovechar tal circunstancia para mejorar su ejercicio político administrativo; incluso cada una de las provincias podía tener su propia Constitución. (QUINTERO, 2002). En esta Constitución -1853-, sin cambiar la conformación del poder ejecutivo, se tendió a disminuir sus atribuciones frente al legislativo. (ORTIZ, 1993).

José María Obando, quien había sido elegido presidente bajo los parámetros de la Constitución de 1843 -presidencialista y de características conservadoras -, a los pocos días de su posesión, tuvo que sancionar el 21 de mayo de 1853, una nueva Constitución. (ALARCÓN, 1999). Entre otros asuntos se estableció la separación entre la iglesia y el Estado, y se consagró la elección popular del presidente y el Vicepresidente. (ALARCÓN, 1999)

El presidente, como jefe de la administración pública, era elegido a través del voto secreto y directo por mayoría relativa de votos. El Vicepresidente, con vocación sucesoral en caso de vacancia temporal o absoluta del titular, se elegía para el mismo período y con las mismas formalidades. (GÓMEZ, 2001)

La figura del Vicepresidente se conservó en esta Constitución para suplir la falta temporal o absoluta del Presidente, en caso de falta temporal o absoluta del Vicepresidente para ejercer el Poder Ejecutivo, era ejercido por un ciudadano Designado anualmente por el Congreso $0^{5}$. La Suprema Corte era la competente para "conocer de las causas contra el Presidente y Vicepresidente de la Nueva Granada y contra el Designado para ejercer el Poder Ejecutivo, por delitos comunes, después de decretada la suspensión por el Senado, a petición de la Cámara de

\footnotetext{
${ }^{5}$ Véase artículos 28 y 29 de la Constitución de la República de la Nueva Granada del 20 de mayo de 1853
} 
MUÑOZ M., PAULA XIMENA (2014): “RESPONSABILIDAD DEL VICEPRESIDENTE DE LA REPÚBLICA EN EJERCICIO DE SUS FUNCIONES CONSTITUCIONALES”, VIA INVENIENDI ET IUDICANDI, Vol. 9, No. 1, pp.

Representantes", de conformidad con el art. 42, numeral $2^{\circ}$ de la Constitución de 1853. (Constitución de la República de la Nueva Granada del 20 de mayo de 1853)

Durante el golpe de Estado de José María Melo en 1854, fue abolida la anterior Constitución y puesta en vigencia la de 1843. Derrotado Melo, se volvió a la Constitución de 1853, la cual no se reformó hasta 1858. (ORTIZ, 1993)

La Constitución del 22 de mayo de 1858 fue una Constitución federal, pero con algunos criterios conservadores. Se buscó en ella reintegrar la unidad nacional dispersa políticamente en los ocho estados subsistentes, y de ahí la definición como Confederación Granadina. En esta Constitución se delimitaron atribuciones del gobierno central y de los administrados de los Estados. (QUINTERO, 2002). Con el ánimo de fortalecer el poder del Congreso, la Constitución de 1958, hizo desaparecer la institución de la Vicepresidencia. (ALARCÓN, 1999). Para el remplazo del presidente de la Confederación, el Poder Ejecutivo lo asumiría uno de los tres Designados, según el art. 42 de la Constitución del 58.

En cuanto a la Constitución liberal, radical y federativa de 1863 no cambió el esquema de tres "designados" - como reemplazo del presidente en sus faltas absolutas o temporales - , pero sí disminuyó poderes al ejecutivo. (ORTIZ, 2005). La Vicepresidencia, durante el período federal (1863-1886), fue borrada del mapa político, cuando el poder ejecutivo fue menos importante que el legislativo y que los poderes regionales. (ORTIZ, 1993)

En 1886 se redactó la Constitución que mayor continuidad ha tenido Colombia, impulsada por el movimiento de la Regeneración Conservadora, presidido por el presidente Rafael Núñez. En esta Constitución se fortalecieron los poderes del ejecutivo y se disminuyeron los poderes del legislativo. (Constituciones que han existido en Colombia. (s.f). Recuperado el 6 de febrero de 2013, de la fuente http://www.banrepcultural.org/blaavirtual/ayudadetareas/poli/poli57.htm) .

Núñez al retirarse de la presidencia el $1^{\circ}$ de abril de 1886, la Carta Política fue sancionada por el General José María Campo Serrano, encargado del Poder Ejecutivo. (QUINTERO, 2002) 
En 1886, fue adoptada nuevamente la figura de la Vicepresidencia, así, las funciones del Vicepresidente se enmarcaron en reemplazar al presidente y presidir el Consejo de Estado ${ }^{6}$. Miguel Antonio Caro, Vicepresidente de la época, ejerció el poder ejecutivo en diversas ocasiones en reemplazo del titular, Rafael Núñez. (OSPINA, 1986)

El Vicepresidente también hacía parte del Consejo de Estado, presidiendo el cuerpo consultivo; al respecto el art. 136 de la Constitución de 1886: "El Consejo de Estado se compondrá de siete individuos, a saber: el Vicepresidente de la República, que lo preside, y seis Vocales nombrados con arreglo a esta Constitución" (Constitución Política de la República de Colombia del 5 de agosto de 1886). Como el Consejo de Estado no era el tribunal supremo de la jurisdicción contencioso administrativa, no existía ninguna contradicción en que un funcionario de origen político como el Vicepresidente, presidiera esta corporación como cuerpo consultivo del gobierno. (ALARCÓN, 1999)

En materia de responsabilidad, el Senado tenía facultades de conocer previa acusación de la Cámara de Representantes, las faltas cometidas por el Vicepresidente; así, el art. 102, numeral $4^{\circ}$ consagró: "Acusar ante el Senado, cuando hubiere justa causa, al Presidente y al Vicepresidente de la República..." (Constitución Política de la República de Colombia del 5 de agosto de 1886). Cuando el Vicepresidente ejerciera la presidencia respondía únicamente por: i) actos de violencia o coacción en elecciones; ii) por actos que impidieran la reunión constitucional de las Cámaras Legislativas, o estorbaran a éstas o a las demás Corporaciones o autoridades públicas establecidas en la Constitución de 1886, y iii) por delitos de alta traición. (RESTREPO, 1995).

Entre 1886 y 1910 fueron Vicepresidentes de la República Eliseo Payan, quien posesionado por ausencia de Rafael Núñez fue rápidamente destituido, porque sus posiciones políticas, todavía asociadas al régimen federal, no

\footnotetext{
${ }^{6}$ Véase artículo 24 de la Constitución del Politica de la República de Colombia del 5 de agosto de 1886 
MUÑOZ M., PAULA XIMENA (2014): “RESPONSABILIDAD DEL VICEPRESIDENTE DE LA REPÚBLICA EN EJERCICIO DE SUS FUNCIONES CONSTITUCIONALES”, VIA INVENIENDI ET IUDICANDI, Vol. 9, No. 1, pp.

concordaban con el pensamiento del partido nacional ni con el del presidente. (ORTIZ, 1993)

Miguel Antonio Caro hizo parte del Consejo Nacional de delegatarios convocados por Rafael Núñez, y se posesionó como Vicepresidente en 1892. Su concepción ideológica fue muy importante para la Constitución de 1886, incluso redactó su texto final. La Vicepresidencia de Caro, hasta 1895 que murió Núñez, constituyó un factor clave para el apoyo al ejercicio presidencial, además de asegurar la continuidad de su partido en el poder. (ORTIZ, 1993). Contrario al aporte de Caro, José Manuel Marroquín, Vicepresidente bajo el gobierno de Manuel Antonio Sanclemente desde julio de 1898, tomó por golpe de Estado a la presidencia el 31 de julio de 1900, en plena guerra de los Mil Días, entre otras razones, por la necesidad de unificar su propio partido frente a los opositores liberales. (ORTIZ, 1993)

La Vicepresidencia fue causa del golpe de Estado. Este caso de indiscutible gravedad hizo pensar a los reformadores del año 1910 que la institución de la Vicepresidencia hacía daño para el ejercicio del Poder Ejecutivo, y así decidió suprimirla, para consagrar las Designaturas primera y segunda, que debían ser provistas por el Congreso cada año". (COPETE, 1960)

Hasta el año 1905 la figura de la Vicepresidencia de la República era un cargo con funciones permanentes y de mucha influencia en el gobierno de turno, constituyéndose en el colaborador más indispensable al presidente de la República, llegando inclusive a presidir por derecho propio el Consejo de Gobierno o de ministros. (ECHAVARRÍA y LOZANO, 1995); sin embargo, ante algunas adversidades y discrepancias entre las dos ramas del poder público, hizo que Reyes, el 13 de diciembre de 1904, clausurara el Congreso, siendo reemplazado por una Asamblea Nacional, convocada por primera vez el $1^{\circ}$ de febrero de 1905 . En 1905, la figura Vicepresidencial fue suprimida del sistema político colombiano a través del Acto Reformatorio No. 5 del 30 de marzo, así como la figura del Designado; de manera que en caso de falta temporal del presidente de la República, designaría un Ministro, y a falta de este, el encargado del poder Ejecutivo estaría en 
MUÑOZ M., PAULA XIMENA (2014): “RESPONSABILIDAD DEL VICEPRESIDENTE DE LA REPÚBLICA EN EJERCICIO DE SUS FUNCIONES CONSTITUCIONALES”, VIA INVENIENDI ET IUDICANDI, Vol. 9, No. 1, pp.

cabeza del Gobernador del Departamento que se hallara más próximo a la capital de la República. (Decreto orgánico de Bolívar. Artículo $7^{\circ} .27$ de agosto de 1828).

El Acto Legislativo número 5 , es sin duda el más significativo dictado por el Gobierno de Reyes, ya que al suprimir los cargos de Vicepresidente, elegido por el pueblo, y del Designado, elegido por el Congreso, dejó la escogencia de quién debía reemplazar al presidente escogido por él en sus faltas temporales; y facultar al Consejo de Ministros para designar al ministro que debiera reemplazar al presidente por falta absoluta. (CÓRDOBA 1998)

El intento de restablecer la Vicepresidencia surgió nuevamente en las comisiones de estudios constitucionales de 1952, 1953 y 1954, cuyos proyectos de enmienda a la Constitución de 1886 son uniformes, tanto del partido liberal como el partido conservador. ${ }^{7}$ (OSPINA, 1986)

Colombia tardó 86 años en adoptar nuevamente la figura de la Vicepresidencia de la República, tema discutido en la Asamblea Nacional Constituyente acerca de su conveniencia en el nuevo Estado Social de Derecho.

\section{La Vicepresidencia en la Constitución de 1991}

En la Asamblea Nacional Constituyente debido a la necesidad de una profunda reforma a la Constitución Nacional, (CENTRO DE ESTUDIOS CONSTITUCIONALES, 1990) dentro de los diferentes temas objeto de discusión, fue analizada la posibilidad de adoptar nuevamente la figura de la Vicepresidencia o continuar con la Designatura ${ }^{8}$.

\footnotetext{
${ }^{7}$ Para OSPINA (1986), la persona llamada a reemplazar al presidente de la República sea en sus faltas temporales o absolutas, es un Jefe de Estado en potencia. En este sentido, el Vicepresidente en remplazo del presidente corresponde hacer su elección a través de la participación democrática de los ciudadanos.

${ }^{8}$ Para ÁLVAREZ (1990: 35) la reforma constitucional en realidad no existió, fue social e interesadamente producto de un invento, en la cual adscribió y atribuyó un conjunto de papeles reordenando a los miembros de una sociedad, frente al tema que ella plantea.
} 
MUÑOZ M., PAULA XIMENA (2014): “RESPONSABILIDAD DEL VICEPRESIDENTE DE LA REPÚBLICA EN EJERCICIO DE SUS FUNCIONES CONSTITUCIONALES”, VIA INVENIENDI ET IUDICANDI, Vol. 9, No. 1, pp.

Tanto en la academia como en los debates de la Constituyente surgieron diferentes propuestas con respecto a éstas dos figuras. Así, VALENCIA (1990: 80) por no encontrase de acuerdo con el temario escogido en el Acuerdo Político sobre la Asamblea Constitucional y el Decreto Legislativo 1926 del 23 de agosto de 1990, propuso en su ensayo -entre otros asuntos- en una perspectiva de democracia radical; adoptar la Vicepresidencia como cargo electivo con funciones permanentes con el ánimo de modernizar y democratizar el régimen de sucesión presidencial vigente y a la vez racionalizar la jefatura del Estado.

En el seno de la subcomisión de la Comisión Tercera de la Constituyente se expusieron los ejes centrales de aquellos a favor y en contra de la Vicepresidencia (GARCÍA, 2005). Los primeros fueron liderados por Carlos Lleras de la Fuente, liberal elegido por el movimiento de Salvación Nacional, acompañado también por el liberal Hernando Herrera en pro de la Designatura; mientras los segundos fueron representados por Antonio Navarro, Abel Rodríguez del M-19 y por José Matías del PRT (GARCÍA, 2005). Las dos posiciones fueron irreconciliables, razón por la cual se redactaron dos ponencias para su discusión. (GARCÍA, 2005: párr. \# 8)

Es de anotar que en la subcomisión tercera de la Asamblea Nacional Constituyente hubo acuerdo en que, de crearse el Vicepresidente, no podrían conferírsele funciones ni en la Constitución ni por el presidente, salvo respecto de este último, la de "dar al Vicepresidente misiones o encargos especiales" (HENAO, 1996); orientación ideológica más acorde con la naturaleza de la nueva institución y el ejercicio unipersonal de la jefatura del Estado. (HENAO, 1996: 253)

Aquellos en favor de la Designatura criticaron la adopción de la Vicepresidencia al considerarla no solamente costosa, sino innecesaria por no tener funciones asignadas más que la de reemplazar al presidente. Opinaron además, que la existencia de un Vicepresidente debilitaría y desdibujaría la figura del presidente. (GARCÍA, 2005: párr. \# 9) Contraria a éstas posiciones, los partidarios de la Vicepresidencia manifestaron que, a pesar que la figura de la Designatura ha funcionado en Colombia, el encargo conferido a la Asamblea Nacional Constituyente fue el de perfeccionar las instituciones democráticas y devolver al pueblo colombiano su soberanía; siendo partidarios de quien debería reemplazar al presidente, fuera un REVISTA VIA INVENIENDI ET IUDICANDI, Vol. 9, No. 1 UNIVERSIDAD SANTO TOMÁS, BOGOTÁ 
MUÑOZ M., PAULA XIMENA (2014): “RESPONSABILIDAD DEL VICEPRESIDENTE DE LA REPÚBLICA EN EJERCICIO DE SUS FUNCIONES CONSTITUCIONALES”, VIA INVENIENDI ET IUDICANDI, Vol. 9, No. 1, pp.

ciudadano elegido popularmente (GACETA CONSTITUCIONAL, 1991, No. 40). El ex delegatario Abel Rodríguez reiteró además que al Vicepresidente no le otorgarían funciones constitucionalmente sino que sería ejecutor de los encargos especiales asignados por el presidente. (GACETA CONSTITUCIONAL, 1991, No. 40).

A su turno, Vásquez Carrizosa consideró más democrática la elección por el pueblo del sucesor del presidente, permitiendo además la racionalización del poder, democratizando más la presidencia, que a su juicio, tiene poderes omnímodos (GACETA CONSTITUCIONAL, 1991, No. 40: 2). Mostró como necesario un Vicepresidente que coadyuvara en las tareas del servicio público al presidente. (GACETA CONSTITUCIONAL, 1991, No. 40: 2).

El proyecto presentado en la Comisión tercera de la Constituyente de aquellos a favor de la Vicepresidencia, fue direccionado de la siguiente manera: i) que el Vicepresidente estuviera en la misma fórmula del presidente, asegurando su participación en la escogencia; ii) la asignación de misiones o encargos especiales del presidente al Vicepresidente y no funciones para evitar disputas entre una y otra dignidad; y iii) la prohibición de asumir funciones de Ministro Delegatario. (GACETA CONSTITUCIONAL, 1991, No. 40).

Las discusiones surgidas en la Asamblea Nacional Constituyente acerca de la adopción de la Vicepresidencia o la Designatura, giraron en torno al comportamiento histórico presentado en el país durante la aparición de una u otra figura, y en cuanto a la forma de elección. Mientras la Designatura sería elegida por el Congreso, la Vicepresidencia tendría el mismo origen de su compañero de fórmula, es decir, por elección popular. Pero nada se dijo acerca de la responsabilidad del Vicepresidente, tal vez porque siempre hubo consenso en que al Vicepresidente aparte de reemplazar al presidente de la República, se le asignarían misiones o encargos especiales y no funciones para evitar enfrentamientos entre el primer mandatario y su segundo a bordo.

La discusión en torno a la adopción o no de la Vicepresidencia de la República fue exclusivamente por el comportamiento a nivel histórico que ha tenido esta figura, y los costos que acarrearía su adopción siendo ésta considerada una institución y un REVISTA VIA INVENIENDI ET IUDICANDI, Vol. 9, No. 1 UNIVERSIDAD SANTO TOMÁS, BOGOTÁ 
MUÑOZ M., PAULA XIMENA (2014): “RESPONSABILIDAD DEL VICEPRESIDENTE DE LA REPÚBLICA EN EJERCICIO DE SUS FUNCIONES CONSTITUCIONALES”, VIA INVENIENDI ET IUDICANDI, Vol. 9, No. 1, pp.

cargo (GACETA CONSTITUCIONAL, 1991, No. 40: 18); contrario a la Designatura, conocida como un cargo, en el cual el Designado no es un funcionario del Estado (GACETA CONSTITUCIONAL, 1991, No. 40).

En definitiva, se adoptó la institución de la Vicepresidencia plasmada en el título VII, cap. III, arts. 202 al 205 de la Constitución Política de Colombia. Con esta disposición normativa fue sustituido el art. 124 de la Constitución de 1886, proveniente del Acto Legislativo 1 de 1945, artículo 8 y del Acto Legislativo 1 de 959, artículo $2^{\circ}$. (LLERAS, C \& TANGARIFE, M, 1996: 777)

Algunos doctrinantes se pronunciaron acerca de la adopción de la figura de la Vicepresidencia en la Carta Política de 1991; según ZUBIRÍA (2011: 194) debió haberse señalado expresamente funciones, tanto en la órbita interna como externa al Vicepresidente de la República, igual como sucede, por ejemplo en Venezuela donde esta figura, revivida en la Constitución de 1999, tiene como atribuciones: coordinar la administración pública nacional; proponer al presidente el nombramiento o remoción, entre otras. Por su parte, el profesor YOUNES (2001) consideró innecesario el cambio de la Designatura a la Vicepresidencia por el manejo que se venía dando al país con la figura del designado.

\section{Vicepresidente como funcionario público}

El concepto de funcionario ha sido acogido en el ordenamiento jurídico colombiano, desde el momento en que varias disposiciones legales han entendido, que el funcionario es un servidor del Estado, como lo hizo el Decreto 1732 de 1960 cuando, ordenó tener por funcionarios o empleados de la rama ejecutiva, a "todas las personas naturales que presten de manera regular sus férvidos en funciones o empleos permanentes no adscritos a rama distinta, creados o autorizados por la Ley y remunerados por el Estado en cualquiera de sus administraciones centrales o seccionales y en los establecimientos públicos. (Consejo de Estado, 28 de abril de 1983). Asimismo, el Decreto 2400 de 1968, art. 2, modificado por el Decreto 3074 de 1978, definió como empleo el conjunto de funciones señaladas por la Constitución, la ley, el reglamento o asignadas por autoridad competente que deben ser atendidas por una persona natural. Atendiendo el art. 122 de la ConstPol al consagrar: "No REVISTA VIA INVENIENDI ET IUDICANDI, Vol. 9, No. 1 UNIVERSIDAD SANTO TOMÁS, BOGOTÁ 
MUÑOZ M., PAULA XIMENA (2014): “RESPONSABILIDAD DEL VICEPRESIDENTE DE LA REPÚBLICA EN EJERCICIO DE SUS FUNCIONES CONSTITUCIONALES”, VIA INVENIENDI ET IUDICANDI, Vol. 9, No. 1, pp.

habrá empleo público que no tenga funciones detalladas en la ley o reglamento", para el Consejo de Estado $^{9}$ empleo público es el conjunto de funciones señaladas por la ConstPol, la ley o el reglamento o asignadas por autoridad competente que deban ser atendidas por una persona natural, con la finalidad de satisfacer las necesidades permanentes de la administración pública.

En síntesis, funcionario público es aquel servidor del Estado que se vincula a través de distintas modalidades; es decir, se trata de un término único y genérico para denominar las personas que prestan sus servicios al Estado sea la persona elegida o nombrada para ejercer un cargo público (CONSEJO DE ESTADO, 27 de septiembre de 1974).

En general, desde un nivel jerárquico y en detalle, no hay elementos normativos específicos o criterios jurídicos concretos que sirvan para elaborar, directamente y con propósitos exhaustivos y prácticos, las nociones legales de los servidores o funcionarios públicos. Igualmente, desde una normatividad superior como la Constitución Política de 1991 se encuentra una noción definida del servidor público, ni aparece con suficiente claridad una clasificación exhaustiva de sus distintas expresiones empleadas, salvo las previstas en los artículos 122, 123 y 124 de la ConstPol. (Corte Constitucional. Sentencia C-484. Magistrado Fabio Morón Díaz; 30 de octubre de 1995). Sin embargo, la Constitución Política de 1991 señala quienes son considerados funcionarios públicos sin que pueda tener cabida a la ocupación de un empleo o cargo público cuando no existan funciones expresamente detalladas. Así, el artículo 122, inc. $1^{\circ}$ ConstPol, establece que no habrá un empleo público sin funciones detalladas en la ley o reglamento; subsiguientemente el art. 123 define aquellos que son considerados servidores públicos, es decir, los miembros de las corporaciones públicas, los empleados y trabajadores del Estado, teniendo el deber implícito de ejercer sus funciones en la forma prevista por la Constitución, la Ley o el reglamento.

La ley 599 del 24 de julio de 2000 por la cual se expide el código penal colombiano, para los efectos de la ley penal, son servidores públicos los miembros de las

\footnotetext{
${ }^{9}$ Consejo de Estado. Consejero ponente: Alfonso Arango Henao; 27 de septiembre de 1974 
MUÑOZ M., PAULA XIMENA (2014): “RESPONSABILIDAD DEL VICEPRESIDENTE DE LA REPÚBLICA EN EJERCICIO DE SUS FUNCIONES CONSTITUCIONALES”, VIA INVENIENDI ET IUDICANDI, Vol. 9, No. 1, pp.

corporaciones públicas, los empleados y trabajadores del Estado y de sus entidades descentralizadas territorialmente y por servicios.

Cabe observar que existen diferencias a nivel constitucional relacionado con un empleado o servidor público y un funcionario público. VILLEGAS (2003) distingue, a partir de la ConstPol, los funcionarios o agentes públicos de los empleados o servidores públicos en que, los primeros tienen autoridad o jurisdicción (art. 99 ConstPol), integran el Gobierno (art. 115 ConstPol), ejercen función política (art. 127 ConstPol), tienen fuero penal especial (art. 173 ConstPol) -En este sentido, le corresponde entre otras atribuciones al Senado: "Admitir o no las renuncias que hagan de sus empleos el Presidente de la República o el Vicepresidente"-, están sometidos a censura (art. 135, num. $8^{\circ}$, ConstPol), ejercen jurisdicción, autoridad civil o política (art. 127 ConstPol); contrario sensu la categoría de los empleados públicos, los cuales no poseen éstas características, dada su naturaleza técnica, auxiliar o administrativa.

El Vicepresidente por ser un cargo de elección popular y por tener funciones constitucionalmente asignadas, a simple vista adopta las características para ser funcionario público, sin embargo, es necesario aclarar si la asignación de dichas funciones son propias del cargo de Vicepresidente.

La consideración del Vicepresidente de la República como funcionario público ha estado dividida; así por ejemplo, los congresistas que debatieron en primer debate el proyecto de Acto Legislativo No.12 de 2004 -propuesta para restablecer la reelección presidencial en Colombia - manifestaron que si bien el Vicepresidente de la República no es en sentido estricto un funcionario público, este podía ser nombrado en cargos del Ejecutivo cuando el presidente así lo decida. (GACETA DEL CONGRESO 176). Desde el punto de vista de la doctrina, ALARCÓN (2009) considera al Vicepresidente un ciudadano común y corriente, igual a todos los mortales, cumpliendo funciones públicas en la medida en que el presidente le confíe "misiones o encargos especiales".

VIDAL y otros (2006) por su parte, aclaran que pese a su alta investidura, no podría el Vicepresidente tener injerencia en la administración nacional ni impartir órdenes o REVISTA VIA INVENIENDI ET IUDICANDI, Vol. 9, No. 1 UNIVERSIDAD SANTO TOMÁS, BOGOTÁ 
MUÑOZ M., PAULA XIMENA (2014): “RESPONSABILIDAD DEL VICEPRESIDENTE DE LA REPÚBLICA EN EJERCICIO DE SUS FUNCIONES CONSTITUCIONALES”, VIA INVENIENDI ET IUDICANDI, Vol. 9, No. 1, pp.

instrucciones, ni fijar políticas, ya que no es un co-gobernador, porque no hace parte del Gobierno según lo establecido por la Carta Política en el art. 115, así como tampoco puede ser removido por este; facultad exclusiva del Congreso de la República. En este sentido y tomando en cuenta las características establecidas por la doctrina para los funcionarios públicos, el Vicepresidente de la República no podría considerarse propiamente un funcionario público.

En otras palabras y teniendo en cuenta la clasificación de los funcionarios públicos y las funciones consagradas por la Constitución al Vicepresidente, este se considera un funcionario público en la medida en que ejerza las misiones o encargos especiales asignados por el presidente de la República, ya que como se ha advertido, es el único evento en el cual funge como Vicepresidente de la República; de otra parte, sería funcionario público cuando ocupe un cargo en la rama ejecutiva, entrando a cumplir las funciones de dicho cargo; o como reemplazo del presidente de la República cuando este incurra en alguna falta temporal o absoluta, evento en el cual, entraría a cumplir funciones como presidente.

Jurisprudencialmente tanto la Corte Constitucional como el Consejo de Estado han hecho pronunciamientos acerca del Vicepresidente como funcionario público. Por un lado, la Corte Constitucional considera la Vicepresidencia como un cargo público; por el otro, el Consejo de Estado considera al Vicepresidente de la República como una figura Sui Generis o de mera expectativa.

La Corte Constitucional en sentencia C-594 del 7 de diciembre de 1995, magistrado ponente Antonio Barrera Carbonell, se pronuncia haciendo una división de las "funciones" constitucionalmente asignadas al Vicepresidente de la República en cuanto al ejercicio de funciones públicas, considerando por su parte que el cargo de Vicepresidente de la República es empleo público, como se deduce del contenido normativo de los arts. 123 y 173. numeral $1^{\circ}$ de la ConstPol señalando:

"Son servidores públicos los empleados y

trabajadores del Estado" (art. 123 ConstPol)

"Son atribuciones del Senado:.. admitir o no las

renuncias que hagan de sus empleos el Presidente de 
MUÑOZ M., PAULA XIMENA (2014): “RESPONSABILIDAD DEL VICEPRESIDENTE DE LA REPÚBLICA EN EJERCICIO DE SUS FUNCIONES CONSTITUCIONALES”, VIA INVENIENDI ET IUDICANDI, Vol. 9, No. 1, pp.

la República o el Vicepresidente" (art. 173, numeral 1 ConstPol).

Al respecto la Corte:

“...lgualmente, la noción responde a la definición que el legislador ha hecho en diferentes oportunidades, en el sentido de que el empleo público comprende el conjunto de funciones, deberes y responsabilidades confiados a una persona natural, en forma subordinada y bajo un régimen jurídico especial, con el fin de satisfacer necesidades permanentes, vinculadas al cumplimiento de las funciones públicas estatales.

De acuerdo con la Constitución las funciones del Vicepresidente son: i) Reemplazar al Presidente de la República en sus faltas temporales y absolutas (incisos $3^{\circ}$ y $4^{\circ}$ del art. 202 ConstPol); ii) Cumplir con las misiones o encargos especiales que le confíe el Presidente de la República (inciso $5^{\circ}$, ibídem); iii) Desempeñar cualquier cargo de la rama ejecutiva para el cual sea designado por el Presidente (inciso $5^{\circ}$, ibídem)..."

En atención al art. 202 de la ConstPol, inc. $3^{\circ}$, el hecho que le corresponda al Vicepresidente reemplazar al presidente de la República en sus faltas temporales y/o absolutas, la Corte acepta la posición de los críticos en razón que el Vicepresidente de la República no desempeña función alguna, mientras no se da el supuesto de reemplazar al presidente, pero afirma que se trata de una función como tal:

"En el primer evento, es obvio, como lo han señalado algunos críticos de la institución de la Vicepresidencia, que su titular propiamente no desempeña función 
MUÑOZ M., PAULA XIMENA (2014): “RESPONSABILIDAD DEL VICEPRESIDENTE DE LA REPÚBLICA EN EJERCICIO DE SUS FUNCIONES CONSTITUCIONALES”, VIA INVENIENDI ET IUDICANDI, Vol. 9, No. 1, pp.

alguna, mientras no se da el supuesto de reemplazar

al Presidente; sin embargo, debe entenderse que la figura fue institucionalizada precisamente bajo la idea de que el Vicepresidente tuviera vocación o se encontrara en disponibilidad de desempeñar las funciones presidenciales en las hipótesis previstas en la Constitución"

Tratándose de las misiones o encargos especiales asignados por el primer mandatario, éstas se concretan en la realización de misiones o encargos específicos, esto es, labores o cometidos concretos asignados. Ahora, en cuanto al ejercicio por parte del Vicepresidente de la República en cualquier cargo de la rama ejecutiva, la Corte Constitucional evidencia que el Vicepresidente cumple las funciones que constitucional, legal o reglamentariamente corresponden al respectivo cargo.

En este orden de ideas, la responsabilidad por el ejercicio de funciones públicas recae sobre el cargo ejercido, es decir, sobre el ejercicio del cargo de presidente o en algún cargo de la rama ejecutiva. Sin embargo, argumenta la Corte según lo expuesto en la sentencia en mención: "(...) que el cargo de Vicepresidente corresponde a un empleo público y que sus funciones están determinadas en la Constitución. Igualmente, que según ésta, es el Presidente la única autoridad que puede asignarle funciones adicionales, bien confiándole misiones o encargos especiales o mediante el mecanismo de la designación en un cargo de la rama ejecutiva"; no siendo tarea del legislador asignarle funciones.

De igual modo, reitera la Corte Constitucional en sentencia 727 del 21 de junio de 2000, al Vicepresidente como un funcionario público:

“El Vicepresidente de la República sí es un cargo público con funciones constitucionales propias 0 asignadas por el presidente de la República, expresamente previsto por la Carta Fundamental". 
MUÑOZ M., PAULA XIMENA (2014): “RESPONSABILIDAD DEL VICEPRESIDENTE DE LA REPÚBLICA EN EJERCICIO DE SUS FUNCIONES CONSTITUCIONALES”, VIA INVENIENDI ET IUDICANDI, Vol. 9, No. 1, pp.

Contraria a la posición adoptada por la Corte Constitucional, el Consejo de Estado $^{10}$ considera la situación jurídica del Vicepresidente de la República "sui generis" dentro de la organización de la rama ejecutiva del poder público del Estado colombiano, pues su vocación constitucional, según las voces del art. 202, inc. $3^{\circ}$ y $5^{\circ}$ ConstPol, es la de reemplazar al presidente de la República en sus faltas temporales o absolutas, aun en el caso de presentarse éstas antes de su posesión:

“... No se trata, en consecuencia, de un funcionario con atribuciones propias, ya que el ejercicio de las mismas está sometido a la condición de que se produzca una falta temporal o absoluta del titular del cargo. Es el reemplazo del Presidente de la República en las hipótesis previstas en la Constitución Política y nada más, las que de presentarse, traen como consecuencia en la vida institucional, la concreción de su vocación sucesoral. Es en dicho momento cuando el Vicepresidente se convierte en funcionario, al tomar posesión del cargo en calidad de Presidente Encargado, durante el término de la falta temporal del titular, o del resto del período, cuando se está en presencia de una falta absoluta".

"Antes de presentarse las hipótesis de faltas absolutas o temporales, se tendrá simplemente a un Vicepresidente electo, aun cuando haya jurado formalmente sobre el cumplimiento de sus funciones Vicepresidenciales, ya que es la posesión como Presidente encargado la que le imprime la condición de funcionario, pues sin el juramento de cumplir $y$ defender la Constitución y desempeñar los deberes que le incumben como Presidente, de acuerdo con el artículo 123 , inciso $2^{\circ}$, de la Constitución Política, no

\footnotetext{
${ }^{10}$ Consejo de Estado. Consejero ponente: Manuel Santiago Urueta; 14 de julio de 1998 
MUÑOZ M., PAULA XIMENA (2014): “RESPONSABILIDAD DEL VICEPRESIDENTE DE LA REPÚBLICA EN EJERCICIO DE SUS FUNCIONES CONSTITUCIONALES”, VIA INVENIENDI ET IUDICANDI, Vol. 9, No. 1, pp.

entrará a ejercer su función constitucional y, en
consecuencia, no será un funcionario público. En fin,
cuando no se presenten faltas temporales o absolutas
del Presidente de la República, el Vicepresidente no
tendrá oportunidad en tal calidad de acceder al
ejercicio de sus funciones constitucionales. Por esta
razón, puede afirmarse que desde el punto de vista
técnico jurídico el Vicepresidente de la República no
es un funcionario público en ejercicio de sus funciones
constitucionales sino una persona con vocación de
suceder al Presidente de la República, cuando se
presentan las circunstancias previstas constitucionalmente para ello".

"...en el evento de que el Vicepresidente sea designado en un cargo de la rama ejecutiva, situación que la norma ha previsto como compatible con la calidad de Vicepresidente, entonces sí, éste se convertirá, adicionalmente, en funcionario del gobierno, sujeto a las situaciones administrativas propias de los servidores públicos. Es así como si el Vicepresidente es designado Ministro, en esta condición hará parte del gobierno, pues éste está integrado por el Presidente de la República, los Ministros del Despacho y los Directores de Departamentos Administrativos, de acuerdo con las previsiones del artículo 115 constitucional..."

Además de ello, advierte el Consejo de Estado ${ }^{11}$, en sentencia del 5 de agosto de 1999, que la Vicepresidencia por ser de creación Constitucional se entiende como órgano en el ejercicio del poder público por parte del Vicepresidente

\footnotetext{
${ }^{11}$ Consejo de Estado. Consejero ponente: Germán Rodríguez Villamizar; 5 de agosto de 1999.
} 
MUÑOZ M., PAULA XIMENA (2014): “RESPONSABILIDAD DEL VICEPRESIDENTE DE LA REPÚBLICA EN EJERCICIO DE SUS FUNCIONES CONSTITUCIONALES”, VIA INVENIENDI ET IUDICANDI, Vol. 9, No. 1, pp.

de la República para alcanzar los fines del Estado -art. $2^{\circ}$ ConstPol-, sin significar que consecuencialmente sea un funcionario público, al respecto:

"El derecho a valer como funcionario del Vicepresidente de la República dista cuando reemplace al presidente en sus faltas temporales o absolutas, caso en el cual ejerce funciones propias como jefe de Estado, o cuando ocupe un cargo en la Rama Ejecutiva asignado por el presidente, efectuándose de este modo una participación política plena en el Estado".

Tanto la Corte Constitucional como el Consejo de Estado, aceptan que el Vicepresidente no desempeña función alguna, mientras no se dé el supuesto de reemplazar al presidente; sin embargo para la Corte es una función como tal reemplazar al presidente, ya que así se institucionalizó la figura, así como ocupar cualquier cargo en la rama ejecutiva y ejercer las misiones especiales confiados por el mandatario de turno.

Según la Corte Constitucional, el Vicepresidente de la República es funcionario público por cuanto no sólo ejerce funciones públicas, sino también porque estas funciones tienen un soporte jurídico válido al ser consagradas expresamente en la ConstPol. Entiende la Corte que si el Vicepresidente se encuentra remplazando al presidente, este entra a ejercer como presidente encargado en cumplimiento de sus funciones; pero desconoce la ausencia de responsabilidad atribuible al Vicepresidente, ya que como presidente encargado, en caso de contravenir la Constitución o las leyes, sería juzgado como Jefe de Estado.

Por el contrario, el Consejo de Estado, asume al Vicepresidente como una figura de mera expectativa, posición que comparte la autora, en la cual, no ejerce ninguna función hasta tanto no se dé el supuesto de reemplazar al presidente; razón por la cual, no existe en este sentido, atribución de responsabilidad al Vicepresidente de la República por cuanto no tiene funciones asignadas propias del cargo, incluso cuando ejerza algún cargo de la rama ejecutiva, porque allí asumiría la titularidad del REVISTA VIA INVENIENDI ET IUDICANDI, Vol. 9, No. 1 UNIVERSIDAD SANTO TOMÁS, BOGOTÁ 
MUÑOZ M., PAULA XIMENA (2014): “RESPONSABILIDAD DEL VICEPRESIDENTE DE LA REPÚBLICA EN EJERCICIO DE SUS FUNCIONES CONSTITUCIONALES”, VIA INVENIENDI ET IUDICANDI, Vol. 9, No. 1, pp.

cargo, sus funciones y responsabilidades. Distinto es considerar al Vicepresidente, en cumplimiento de las misiones o encargos especiales asignados por el presidente, evento en el cual podría ser sujeto de responsabilidad por el ejercicio de su cargo.

En consecuencia de lo anterior, el Vicepresidente es funcionario público únicamente cuando se encuentre ejerciendo las misiones o encargos asignados por el presidente de la República, considerada como una atribución propia del cargo.

\section{El Vicepresidente de la República como sujeto responsable}

En el ordenamiento jurídico colombiano, la responsabilidad parte primeramente en la ConstPol arts. $4^{\circ}, 6^{\circ}$ y 198 , expresando la obligación por parte de todos los servidores públicos y en general todas las personas residentes en Colombia, sean estos nacionales o extranjeros, de ser responsables por sus actos $u$ omisiones, por violación a la Constitución y a la ley. Ya el artículo $2^{\circ}$ de la ConstPol, al referirse a los principios fundamentales, señaló de antemano no sólo la finalidad esencial del Estado en relación con la comunidad y la prosperidad general, sino el específico de las autoridades en Colombia para proteger a todos los residentes en el país en sus vidas, honra, bienes, creencias y demás derechos y libertades, consagrando de esta manera la figura de la responsabilidad de los servidores públicos en general. (HERRERA, 2004)

El artículo $6^{\circ}$ de la misma Carta, consagra la responsabilidad de los servidores públicos ante las autoridades, no sólo por infringir la Constitución y las leyes como los particulares, sino también por omisión o extralimitación en el ejercicio de sus funciones. (HERRERA, 2004)

GÓMEZ (2001) entiende la responsabilidad desde el punto de vista de las obligaciones o funciones derivadas de un cierto cargo o relación cuando se trata de funcionarios públicos, según lo expuesto también por NINO (2007); entonces, se es responsable bajo el entendido del ordenamiento jurídico colombiano, por infringir la Constitución y las leyes.

Como común denominador al tema de responsabilidad, la Constitución Política de 1991 prevé la conducta de los individuos y la responsabilidad como REVISTA VIA INVENIENDI ET IUDICANDI, Vol. 9, No. 1 UNIVERSIDAD SANTO TOMÁS, BOGOTÁ 
MUÑOZ M., PAULA XIMENA (2014): “RESPONSABILIDAD DEL VICEPRESIDENTE DE LA REPÚBLICA EN EJERCICIO DE SUS FUNCIONES CONSTITUCIONALES”, VIA INVENIENDI ET IUDICANDI, Vol. 9, No. 1, pp.

consecuencia de sus actos que pueda afectar o perjudicar el normal funcionamiento de la administración del Estado; asignando, según el art. 124 ConstPol, a la ley como la encargada de determinar la responsabilidad de los servidores públicos y la manera de hacerla efectiva, al respecto: "La ley determinará la responsabilidad de los servidores públicos y la manera de hacerla efectiva". Cuando se tiene en cuenta la noción de funcionario público en general o de aquel que presta servicios al Estado en cumplimiento de sus fines, esta definición no se puede escindir de la responsabilidad y de la asunción de consecuencias por las irregularidades que cometa. (IVANEGA, 2007). La responsabilidad de los funcionarios públicos se toma en dos sentidos, como control y como garantía. Por un lado es garantía de y hacia los ciudadanos, y por otro es un principio de orden y un instrumento de control de poder. (REBOLLO, 2001)

En general, la responsabilidad de los encargados de todo poder público, es otro medio de prevenir sus abusos. Todo el que es depositario o delegatario de una parte de la soberanía popular, debe ser responsable de infidelidad o abusos cometidos en su ejercicio. (ALBERDI, 1983)

En este sentido, para que la responsabilidad sea un hecho verdadero, y no una simple palabra, debe estar determinada por la ley con toda precisión; señalando sanciones sea por abuso de los mandatarios o de aquel que ejerza funciones públicas en cumplimiento de los fines del Estado, so pena, de tornarse ineficaz; al respecto ALBERDI (1983):

“...deben existir penas señaladas para los
abusos de los mandatarios, jueces que las
apliquen y leyes que reglen el procedimiento del
juicio político. Sin estos requisitos la
responsabilidad es ineficaz; y el abuso, alentado
por la impunidad nacida del vicio de la
legislación, viene a encontrar más tarde un
castigo en la insurrección, remedio más costoso
a la libertad que lo aplica, que al poder que lo
recibe". (p. 86$)$

De la misma manera, para Kelsen (1949), un individuo es responsable cuando es susceptible de ser sancionado; es decir, se es responsable cuando, según el ordenamiento jurídico, deba aplicarse al individuo una sanción. 


\begin{abstract}
A. Responsabilidad del Vicepresidente a la luz de la Constitución Política de 1991
\end{abstract}

De conformidad con las funciones enmarcadas constitucional y legalmente para el cargo de Vicepresidente, y en razón al concepto de responsabilidad, a continuación se analizarán los diferentes tipos de responsabilidad en los que se cree podría incurrir el Vicepresidente de la República, por el ejercicio de las funciones constitucionalmente asignadas, teniendo en cuenta, según lo expresado anteriormente, cuándo es considerado como funcionario público y cuándo se atribuye como una figura de mera expectativa:

\title{
1. Responsabilidad Disciplinaria
}

De acuerdo con la investidura del Vicepresidente de la República en ejercicio de funciones asignadas bien sea por la ConstPol o por Decreto, corresponde al Procurador General de la Nación -según art. $7^{\circ}$ inc. $1^{\circ}$ num. 22 del Decreto 262 del 22 de febrero de $2000^{12}$-, conocer en única instancia los procesos disciplinarios que se adelanten contra el Vicepresidente.

Si bien es cierto, el Vicepresidente como responsable de las funciones derivadas de su cargo, puede ser sancionado por el máximo exponente del Ministerio Público; como se expuso en el capítulo segundo y tercero de la presente investigación, el sujeto a cargo de la Vicepresidencia, ejerce como Vicepresidente en cumplimiento de las misiones o encargos confiados por el Primer Mandatario, razón por la cual, el Procurador General de la Nación solo estaría facultado a sancionar al Vicepresidente por incumplimiento de las directrices del presidente de la República. Ello se debe a que el Vicepresidente de la República es funcionario público cuando ejerce misiones o encargos especiales confiados por el presidente, ya que allí actúa

\footnotetext{
${ }^{12}$ Por el cual se modifican la estructura y la organización de la Procuraduría General de la Nación y del Instituto del Ministerio Público; el régimen de competencias interno de la Procuraduría General; se dictan normas para su funcionamiento; se modifica el régimen de carrera de la Procuraduría General de la Nación, el de inhabilidades e incompatibilidades de sus servidores y se regulan las diversas situaciones administrativas a las que se encuentran sujetos.
} 
MUÑOZ M., PAULA XIMENA (2014): “RESPONSABILIDAD DEL VICEPRESIDENTE DE LA REPÚBLICA EN EJERCICIO DE SUS FUNCIONES CONSTITUCIONALES”, VIA INVENIENDI ET IUDICANDI, Vol. 9, No. 1, pp.

como Vicepresidente, distinto cuando se encuentre remplazando al primer mandatario o en ejercicio de algún cargo de la rama ejecutiva.

Para BRITO (2007), el Vicepresidente de la República no es sujeto del régimen disciplinario. Esto tiene su explicación y razón de ser, en que este cargo carece de funciones, además no está previsto en ninguna parte del ordenamiento que el Vicepresidente actúe como tal. Es claro que cuando actúa, no lo hace en condición de Vicepresidente sino para atender las misiones o encargos especiales que, conforme al artículo 202 inc. $5^{\circ}$ ConstPol, le confíe el Presidente, en cuyo caso es investigable y se puede sancionar disciplinariamente, pero por el desempeño de tales funciones. Para ALARCÓN (1999), el Vicepresidente, como lo argumenta BRITO (2007), cumple funciones públicas solamente cuando ejerce los encargos o misiones confiados por el presidente, caso en el cual estaría bajo los parámetros de ser investigado como Vicepresidente.

Para que el Vicepresidente de la República sea sancionado disciplinariamente es necesario que ejerza funciones propias como Vicepresidente, y no como presidente o como titular de algún cargo de la rama ejecutiva.

\section{Responsabilidad como Presidente de la República}

Dentro de las funciones constitucionales del Vicepresidente de la República, está la de reemplazar al presidente cuando este se encuentre inmerso en una falta temporal como la licencia o la enfermedad; o absoluta, cuando su renuncia sea aceptada, muera, sea decretada su destitución por sentencia, por incapacidad física permanente o por el abandono del cargo. En este sentido, el Vicepresidente al momento de la ocurrencia de algunas de estas faltas, entra a ejercer el cargo de presidente de la República con todas sus prerrogativas hasta adquirir la calidad de aforado.

En este sentido, la responsabilidad del Vicepresidente estaría dada por el ejercicio del cargo como Presidente de la República en caso de infringir la Constitución o las leyes. Al respecto el art. 198 ConstPol consagra: "El Presidente de 
MUÑOZ M., PAULA XIMENA (2014): “RESPONSABILIDAD DEL VICEPRESIDENTE DE LA REPÚBLICA EN EJERCICIO DE SUS FUNCIONES CONSTITUCIONALES”, VIA INVENIENDI ET IUDICANDI, Vol. 9, No. 1, pp.

la República, o quien haga sus veces, será responsable de sus actos u omisiones que violen la Constitución o las leyes."

En virtud de la calidad como presidente, en caso de actuar contrario a los preceptos constitucionales y legales, será el Senado, previa acusación de la Cámara de Representantes, el encargado de iniciar investigación para el juicio de responsabilidad, atendiendo los preceptos del artículo 178, num. $3^{\circ}$ ConstPol. En este orden de ideas, el inicio de la investigación solo procede por delitos cometidos en ejercicio de sus funciones como presidente o por indignidad por mala conducta y, al respecto, el Senado puede imponerle únicamente la sanción de destitución del empleo o la de privación temporal o pérdida absoluta de derechos políticos.

Visto de otro modo, la responsabilidad adquirida por el Vicepresidente en reemplazo del primer mandatario, es en virtud de fungir como Jefe del Ejecutivo, y no en ejercicio de la Vicepresidencia, ya que desplaza este cargo para entrar a ejercer como Jefe de Estado, Jefe de Gobierno y Suprema Autoridad Administrativa.

3. Responsabilidad del Vicepresidente por delegación constitucional

La figura de la delegación se entiende como una técnica de manejo administrativo de las competencias que autoriza la ConstPol en diferentes normas arts. 209, 211, 196 inciso $4^{\circ}$ y 305-, algunas veces de modo general, otras de manera específica, en virtud de la cual, se produce el traslado de competencias de un órgano que es titular de las respectivas funciones a otro, para que sean ejercidas por éste, bajo su responsabilidad, dentro de los términos y condiciones que fije la ley. Corte Constitucional. Sentencia C-382 del 5 de abril de 2000. Expedientes D3770 y D-3775 M.P. Antonio Barrera Carbonell.

Sin embargo, a pesar que el traslado de competencias de un órgano a otro constituye la regla general cuando se considere necesario, la figura de la delegación no es procedente en todos los casos. En este sentido, y tratándose específicamente del ejercicio de funciones del Vicepresidente, cuando este ejerce las misiones o encargos asignados por el presidente de la República, no puede ser considerada esta función precisamente como producto de una delegación de funciones por parte del primer mandatario. 
Lo anterior, tiene fundamento en el desarrollo e interpretación del art. 211 ConstPol, teniendo en cuenta la consideración por parte de la Corte Constitucional al manifestar que los únicos que tienen aptitud para ser delegatarios del presidente son los ministros, directores de departamentos administrativos, representantes legales de las entidades descentralizadas, superintendentes, gobernadores, alcaldes y agencias del Estado que la misma ley determine. Sentencia C-802. Magistrado Manuel José Cepeda Espinosa; 27 de septiembre de 2006.

En este orden de ideas, el Vicepresidente no se encuentra facultado para ser delegatario del presidente, a menos que se encuentre como titular de algún cargo de la rama ejecutiva, evento en el cual, podría adquirir funciones delegadas no como Vicepresidente sino como titular de uno de estos cargos. Por otro lado, La misma Constitución Política limita expresamente al Vicepresidente de la República para asumir funciones como Ministro Delegatario, al consagrar en el inciso $6^{\circ}$ del art. 202 ConstPol: “...El Vicepresidente no podrá asumir funciones de Ministro Delegatario”. Este último será el encargado de ejercer bajo su propia responsabilidad las funciones constitucionales delegadas por el presidente, tanto aquellas que le son propias como las ejercidas en su calidad de jefe de gobierno ${ }^{13}$.

Aunado a lo anterior, la Corte Constitucional manifiesta la improcedencia de delegación de funciones en dos circunstancias: i) para el ejercicio de la actividad o la competencia de la integridad de la investidura presidencial, o ii) cuando la delegación supone transferir aquéllas atribuciones que atañen con el señalamiento de las grandes directrices, orientaciones y fijación de políticas generales que corresponden como jefe superior de la entidad estatal: “...pues, lo que realmente debe ser objeto de delegación, son las funciones de mera ejecución, instrumentales u operativas". Sentencia C-382. Magistrado Antonio Barrera Carbonell; 5 de abril de 2000.

Sin embargo, teniendo en cuenta la Constitución Política en cuanto a la atribución de funciones al Vicepresidente, al ser confiadas misiones o encargos

\footnotetext{
${ }^{13}$ Véase art. 196 Constitución Política de Colombia. 
MUÑOZ M., PAULA XIMENA (2014): “RESPONSABILIDAD DEL VICEPRESIDENTE DE LA REPÚBLICA EN EJERCICIO DE SUS FUNCIONES CONSTITUCIONALES”, VIA INVENIENDI ET IUDICANDI, Vol. 9, No. 1, pp.

especiales por parte del Presidente de la República, quien actúa como gestor de dichos encargos; a pesar del impedimento del Vicepresidente de asumir funciones de Ministro Delegatario, para la Corte Constitucional en Sentencia C-561. Magistrado Alfredo Beltrán Sierra; 4 de agosto de 1999, consideró viable - en aquel momento histórico- la delegación de funciones por el presidente al Vicepresidente en forma transitoria o permanente, así como la posibilidad de encargarlo de funciones temporales. Sin embargo, la Corte corrigió en Sentencia C-802 de 2006, al expresar que los únicos aptos para ser delegatarios del jefe del Ejecutivo son los ministros, directores de departamentos administrativos, representantes legales de las entidades descentralizadas, superintendentes, gobernadores, alcaldes y agencias del Estado que la misma ley determine. Lo cierto es que el Vicepresidente al no ejercer las misiones o encargos especiales confiados por el presidente producto de una delegación constitucional de sus funciones, no existe responsabilidad atribuible en este caso.

Por otro lado, el Vicepresidente es el encargado de presidir la Comisiones Intersectoriales ${ }^{14}$ creadas para la coordinación y orientación superior de la ejecución de ciertas funciones y servicios públicos de conformidad con la ley 489 de 1998, art. 45, que por tratarse de atribuciones delegadas por el Gobierno, entraña suyos deberes y responsabilidades, entendiendo la delegación por parte del Gobierno Nacional entendida desde la coordinación y orientación superior de la Comisión, Al respecto el Consejo Estado, Sala de Consulta y Servicio Civil, del 3 de diciembre de 2009:

“... en este sentido, la facultad que el artículo 45 de la ley 489 da al Gobierno Nacional para delegarle funciones a la Comisión ha de ser entendida $y$ ejercida en el marco de la expresión "coordinación y orientación superior" para que los integrantes de la Comisión reciban directrices orientadas a "la ejecución de ciertas funciones y servicios públicos" que les correspondan, por lo que habrá de revisarse en cada caso el contenido, la pertinencia y las condiciones de la delegación".

\footnotetext{
${ }^{14}$ Actualmente existen tres comisiones intersectoriales: i) Comisión Colombiana del Océano; ii) Comisión Colombiana del Espacio; iii) Comisión intersectorial para la prevención del reclutamiento, la utilización y la violencia sexual contra niños, niñas, y adolescentes por grupos organizados al margen de la ley y grupos delictivos organizados.
} 
MUÑOZ M., PAULA XIMENA (2014): “RESPONSABILIDAD DEL VICEPRESIDENTE DE LA REPÚBLICA EN EJERCICIO DE SUS FUNCIONES CONSTITUCIONALES”, VIA INVENIENDI ET IUDICANDI, Vol. 9, No. 1, pp.

En este evento, por tratarse de la coordinación y orientación superior de la ejecución de ciertas funciones y servicios públicos, la responsabilidad está establecida por el ejercicio del cargo de conformidad con las funciones delegadas, respondiendo en este caso el Vicepresidente en materia disciplinaria.

\section{Vicepresidente como responsable penal}

Para todos los efectos de la ley penal, son servidores públicos los miembros de las corporaciones públicas, los empleados y trabajadores del Estado y de sus entidades descentralizadas territorialmente y por servicios ${ }^{15}$; en este contexto, el Vicepresidente de la República, en cuanto a responsabilidad en materia penal se trata, podría ser objeto de investigación penal en dos sentidos: el primero de ellos, en caso tal que haya utilizado para la campaña bienes del Estado o recursos del Tesoro Público distintos de aquellos ofrecidos en condiciones de igualdad a todos los candidatos ${ }^{16}$, y podría ser sujeto de investigación penal por la comisión de delitos contra la administración pública en general.

Para que el Vicepresidente pueda ser investigado penalmente, es necesario tener claridad si el delito atribuido fue cometido en ejercicio de sus funciones; de lo contrario será sujeto de investigación penal no como Vicepresidente, sino como particular.

En este orden de ideas, la competencia para investigar y juzgar penalmente al Vicepresidente depende de la naturaleza de la función que desempeñe, y así tenemos que si ejerce funciones presidenciales, lo investiga la cámara de representantes a través de la Comisión de Investigación y lo juzga el Senado artículos 174 y 178 de la ConstPol; si es designado ministro lo investiga la fiscalía y lo juzga la Sala Penal de la Corte Suprema - artículo 235 de la ConstPol- y; si sólo es Vicepresidente a quien se le ha confiado misiones o encargos diferentes a la de Jefes de misión diplomática o consular, lo investiga la Fiscalía y lo juzga, según el delito, los jueces penales del circuito especializados, los penales del circuito y los penales especializados. (LESMES; 2004, pp. 227)

\footnotetext{
${ }^{15}$ Véase artículo 20, ley 599 del 24 de julio de 2000 por la cual se expide el código penal.

${ }^{16}$ Véase Constitución Política de Colombia, art. 127 último inciso. 


\section{Responsabilidad política del Vicepresidente}

La responsabilidad política no se trata de un juicio penal ya que no juzga un hecho delictuoso, sino una situación de gobierno inconveniente para el Estado. (HUENCHIMAN, 2003) El juicio político tiende a la identificación de determinadas conductas cometidas por los servidores públicos que han incurrido en arbitrariedades o abuso de poder, que atentan contra la forma del Estado y Sistema de Gobierno de un país determinado. (Vásquez, 1994)

GARCÍA (1998) concibe la responsabilidad política como un producto de la civilización, plasmada en la sustitución de la responsabilidad jurídica, vale decir penal, por un espécimen de nueva generación. Se diferencia la responsabilidad política de la responsabilidad penal, en que la primera es objetiva, la cual no nace del dolo o de la culpa, siendo por tanto ajena a cualquier responsabilidad jurídica.

En Colombia, dos son las causas de juicio político: cometer delitos en ejercicio de funciones públicas, e incurrir en indignidad por mala conducta. (LICONA, 2007), sin embargo, la responsabilidad política no es atribuible a todos los funcionarios públicos.

Al respecto, el art. 174 de la ConstPol señala quienes podrían ser acusados de responsables políticos, a saber: "Corresponde al Senado conocer de las acusaciones que formule la Cámara de Representantes contra el Presidente de la República o quien haga sus veces; contra los Magistrados de la Corte Suprema de Justicia, del Consejo de Estado y de la Corte Constitucional, los miembros del Consejo Superior de la Judicatura y el Fiscal General de la Nación, aunque hubieren cesado en el ejercicio de sus cargos. En este caso, conocerá por hechos u omisiones ocurridos en el desempeño de los mismos.

A su vez, la ley $5^{\circ}$ de 1992 , art. $6^{\circ}$ num. 4 , previene la facultad del Congreso para desempeñar la función judicial de juzgar excepcionalmente a los altos funcionarios del Estado por responsabilidad política, sin que para este tipo de proceso por indignidad, le sean aplicables normas de carácter penal previstas para 
MUÑOZ M., PAULA XIMENA (2014): “RESPONSABILIDAD DEL VICEPRESIDENTE DE LA REPÚBLICA EN EJERCICIO DE SUS FUNCIONES CONSTITUCIONALES”, VIA INVENIENDI ET IUDICANDI, Vol. 9, No. 1, pp.

otro tipo de juicios, al respecto la Corte Constitucional en sentencia C-369 del 26 de mayo de 1999:

\begin{abstract}
“...el proceso por indignidad es "un juicio de responsabilidad política", para el cual el Reglamento del Congreso prevé un trámite específico, que incluye que la acusación que se presente como tal deba ser probada, que la garantía del derecho a la defensa del acusado se respete, y que si hay lugar a ello eventualmente se produzca la imposición de una sanción tan drástica como la destitución del empleo, o la privación temporal o absoluta de los derechos políticos, es claro que a dicho trámite no le son aplicables las normas de carácter penal previstas para otro tipo de juicios".
\end{abstract}

Como bien lo advierte la norma constitucional, el presidente de la República por ser de elección democrática debe y es políticamente responsable frente al pueblo que lo eligió ya que a éste debe su investidura y no al Congreso LICONA (2007); lo mismo podría decirse del Vicepresidente, ya que por haber sido elegido popularmente el mismo día y en la misma fórmula del presidente, recae sobre él, la responsabilidad frente a sus electores. Sin embargo, teniendo en cuenta la Constitución Política de 1991 art. 174, el Vicepresidente no puede ser sujeto de responsabilidad política, lo será solo en la medida en que se encuentre ejerciendo funciones como presidente por el hecho de infringir de manera grave y ostensible su compromiso con el electorado o el régimen político.

Cabe decir entonces, que el Vicepresidente de la República solo podrá ser juzgado en juicio político por el Senado previa acusación de la Cámara de Representante, cuando se encuentre reemplazando al presidente de la República, ya que en el evento en que el Vicepresidente esté en cumplimiento de las misiones o encargos confiados por el presidente, la Constitución Política de 1991 no prevé al Vicepresidente en ejercicio de sus funciones como sujeto de responsabilidad política. De haber sido aprobada la reforma a la justicia ${ }^{17}$, el Vicepresidente gozaría de fuero constitucional, quedando facultado el Senado de conocer las acusaciones por parte de la Cámara contra éste, lo mismo de acusaciones por indignidad política.

\footnotetext{
${ }^{17}$ Proyecto de ley No. 143 de 2011 Cámara, 007 de 2011 Senado. Por medio del cual se propuso reformar artículos de la Constitución Política con relación a la administración de justicia y otras disposiciones. Diario Oficial No. 48364, archivado en sesión extraordinaria el 28 de junio de 2012. Acta Plenaria No. 136.
} 
MUÑOZ M., PAULA XIMENA (2014): “RESPONSABILIDAD DEL VICEPRESIDENTE DE LA REPÚBLICA EN EJERCICIO DE SUS FUNCIONES CONSTITUCIONALES”, VIA INVENIENDI ET IUDICANDI, Vol. 9, No. 1, pp.

Ahora, distinto sería cuando el Vicepresidente se encuentre ejerciendo un cargo en la rama ejecutiva como ministro, ya que sí sería sujeto de control político en el cual, se faculta al Senado y a la Cámara de Representantes, de proponer la moción de censura por asuntos relacionados con funciones propias del cargo, de conformidad con el art. 135 , num. $8^{\circ}$ y $9^{\circ}$ ConstPol, evento en el cual si es aprobada la moción, podrá ser separado de su cargo; al respecto art. 135, num. 9 ConstPol:

"Proponer moción de censura respecto de los Ministros, Superintendentes y Directores de Departamentos Administrativos por asuntos relacionados con funciones propias del cargo, $O$ por desatención a los requerimientos y citaciones del Congreso de la República. La moción de censura, si hubiere lugar a ella, deberá proponerla por lo menos la décima parte de los miembros que componen la respectiva Cámara. La votación se hará entre el tercero y el décimo día siguientes a la terminación del debate, con audiencia pública del funcionario respectivo. Su aprobación requerirá el voto afirmativo de la mitad más uno de los integrantes de la Cámara que la haya propuesto. Una vez aprobada, el funcionario quedará separado de su cargo. Si fuere rechazada, no podrá presentarse otra sobre la misma materia a menos que la motiven hechos nuevos. La renuncia del funcionario respecto del cual se haya promovido moción de censura no obsta para que la misma sea aprobada conforme a lo previsto en este artículo. Pronunciada una Cámara sobre la moción de censura su decisión inhibe a la otra para pronunciarse sobre la misma”. Negrilla fuera del texto.

Cabe preguntarse: ¿qué pasaría en el evento en que el Vicepresidente, quien se encuentra ejerciendo el cargo como ministro, le sea aprobada la moción de 
MUÑOZ M., PAULA XIMENA (2014): “RESPONSABILIDAD DEL VICEPRESIDENTE DE LA REPÚBLICA EN EJERCICIO DE SUS FUNCIONES CONSTITUCIONALES”, VIA INVENIENDI ET IUDICANDI, Vol. 9, No. 1, pp.

censura?, ¿volvería el sujeto al cargo como Vicepresidente, o la separación del cargo implicaría la de ministro y la de Vicepresidente?

Es evidente que existe un vacío constitucional en la materia, por lo tanto, se propone modificar la Constitución Política de 1991 a través de un Acto Legislativo que especifique no solo las funciones del Vicepresidente, sino también qué hacer con este cargo en caso de ser condenado como responsable por el ejercicio de las funciones sea en algún cargo de la rama ejecutiva, o en remplazo del presidente; es decir, si el sujeto responsable por el ejercicio de funciones como presidente o en algún cargo de la rama ejecutiva, puede reasumir las funciones como Vicepresidente o si por el contrario, subsidiariamente a la condena de responsabilidad pierde las facultades y funciones como segundo a bordo.

\section{Conclusiones}

La Vicepresidencia de la República históricamente ha sido implementada en el ordenamiento jurídico colombiano, para reemplazar al presidente de la República en sus faltas temporales o absolutas, y como soporte para aumentar los poderes del Ejecutivo, sin que el Estado caiga en una administración bipersonal.

Al Vicepresidente de la República en la Constitución de 1991, no le fueron asignadas funciones para el desempeño propio de su cargo salvo las misiones o encargos especiales asignados por el presidente de la República, evitando disputas entre una u otra indignidad, razón por la cual, es el único evento en el cual es considerado como funcionario público, respondiendo en materia disciplinaria.

Es este sentido, al no ser asignadas funciones propias del cargo al Vicepresidente de la República, la responsabilidad está dada por el desempeño de las misiones o encargos especiales asignados por el presidente de la República; y cuando se presente la asignación en cualquier cargo de la rama ejecutiva, responde de acuerdo al ejercicio de funciones administrativas que constitucional y legalmente han sido asignadas para el cargo en particular, y no como Vicepresidente. 
MUÑOZ M., PAULA XIMENA (2014): “RESPONSABILIDAD DEL VICEPRESIDENTE DE LA REPÚBLICA EN EJERCICIO DE SUS FUNCIONES CONSTITUCIONALES”, VIA INVENIENDI ET IUDICANDI, Vol. 9, No. 1, pp.

Existe un vacío Constitucional y jurídico para determinar cuándo el Vicepresidente de la República es sujeto responsable por el ejercicio de sus funciones constitucionales asignadas, que en el caso de ser condenado responsable por el ejercicio de funciones en remplazo del presidente o en algún cargo de la rama ejecutiva, no es posible establecer si continúa como Vicepresidente o por el contrario, queda destituido del cargo. Así las cosas, es necesario hacer una reforma Constitucional en la cual no solo se especifiquen las funciones propias del Vicepresidente, sino también la responsabilidad atribuible en caso de contravenir la Constitución Política y/o a las leyes y las implicaciones de ser declarado responsable. En el evento de lograrse una reforma constitucional, y tomando en consideración la democratización del Ejecutivo, podría considerarse que el Vicepresidente de la República se encargara de reemplazar al presidente de la República en sus faltas temporales o absolutas, considerada ésta como su única función, toda vez que evitaría no solo una administración bipersonal del Estado, sino también extralimitación de funciones.

Considerando la importancia de democratización del ejecutivo y en aras de evitar conflictos entre el mandatario de turno y el segundo a bordo, este último debería pertenecer al mismo partido o movimiento político del presidente de la República, como en el caso de exigencia por parte de la Constitución del Ministro Delegatario. 
MUÑOZ M., PAULA XIMENA (2014): “RESPONSABILIDAD DEL VICEPRESIDENTE DE LA REPÚBLICA EN EJERCICIO DE SUS FUNCIONES CONSTITUCIONALES”, VIA INVENIENDI ET IUDICANDI, Vol. 9, No. 1, pp.

\section{Bibliografía}

ALARCÓN, (1999). Los Segundos a bordo. Bogotá D.C.: Planeta Colombia. S.A.

ALBERDI, J. (1983). Elementos del Derecho Público provincial. República de Argentina: Imprenta del Mercurio.

ÁlVAREZ, Fernando. (1990). El porqué de la reforma Constitucional. Centro de Estudios Constitucionales. Bogotá D.C.: Temis S.A.

BRITO, Themys. (s.f.). En qué se desempeña el Vicepresidente. Recuperado el 6 de marzo de 2012, de la fuente http://politica.about.com/od/Generales/a/En-Qu-ESe-Desempe-Na-El-Vicepresidente.htm

BRITO, Fernando. 2004. La administración Nacional. Estudio de los textos de la Constitución de 1991.

BRITO, Fernando. 2007. Situación disciplinaria del Vicepresidente de la República. Recuperado de la fuente el 11 de abril de 2011. http://www.procuraduria.gov.co/html/columnistas2007/columnistas octubre.html.

Cámara de Representantes. (2012). Proyecto Acto Legislativo 046 por medio del cual se elimina la figura de la Vicepresidencia y se crea la institución de la Designatura. Recuperado el 11 de enero de 2013, del sitio Web: http://servoaspr.imprenta.gov.co:7778/gacetap/gaceta.mostrar documento?p tipo=0

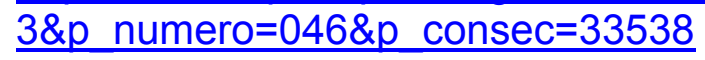

CÓRDOBA, M. Luis. (1998). Apuntes de historia Constitucional y Política de Colombia. Colección de Estudios Históricos. Bogotá D.C.: Universidad Jorge Tadeo Lozano.

CORREDOR P., Lesmes. (2007). Anotaciones sobre Constitución y Gobierno. Montería - Córdoba: Universidad del Sinu.

CÁRDENAS, Hugo. (2011). Analistas consideran que Angelino Garzón no ha hecho más que darle dinamismo a su cargo. El País. Recuperado el 16 de abril de 2012 de la fuente: http://www.elpais.com.co/elpais/colombia/noticias/analistas-consideranangelino-garzon-ha-hecho-darle-dinamismo-su-cargo

Constitution of the United States of America. Recuperado el 13 de febrero de 2013, de la fuente: http://www.constitution.org/constit_htm.

DE LA CALLE, Humberto. (2011). Como está el cargo de Vicepresidente es como un alma en pena. El Nuevo Siglo. Recuperado el 5 de junio de 2011, de la fuente: http://elnuevosiglo.com.co/home/noticias-del-dia/195-noticia-del-dia/32770-comoesta-el-cargo-de-vicepresidente-es-como-una-alma-en-pena-de-la-calle.html 
MUÑOZ M., PAULA XIMENA (2014): “RESPONSABILIDAD DEL VICEPRESIDENTE DE LA REPÚBLICA EN EJERCICIO DE SUS FUNCIONES CONSTITUCIONALES”, VIA INVENIENDI ET IUDICANDI, Vol. 9, No. 1, pp.

DEVIS, Consuelo. (1991). El presidencialismo y la carta del 91. En Señal Editora. Doce ensayos sobre la Nueva Constitución. Medellín: Señal Editora.

ECHAVARRÍA, Astrid; LOZANO, Marta. (1995). Vicepresidencia: ¿Adorno o funcionalidad? Revista Cambio 16, No. 98, p 196 - p 206.

GACETA CONSTITUCIONAL. (1991) No. 40 y 76.

GARCÍA, Daniel. (2005). ¿Qué nos significa la Vicepresidencia? : Cómo se gestó en la Constituyente y qué puede esperarse del Vicepresidente. Recuperado el 4 de junio de 2011, de la fuente http://www.banrepcultural.org/blaavirtual/revistas/credencial/marzo1993/marzo1.htm

GARCÍA, M. Joaquín. (1998). Responsabilidad política y responsabilidad penal. En: Revista Española de Derecho Constitucional.

GARVEY, Todd. A Constitutional Anomaly: Safeguarding Confidential National Security Information Within the Enigma That Is the American Vice Presidency. 17 Wm. \& Mary Bill of Rts. J. 565. Recuperado el 13 de febrero, de la fuente: http://scholarship.law.wm.edu/wmborj/vol17/iss2/11

GÓMEZ, De Antonio. (2001). Pedagogía Constitucional. Un análisis jurídico-político de la Constitución de 1991. Bogotá D.C.: Fundación Universidad de Bogotá Jorge Tadeo Lozano.

GÓMEZ, Alfonso. (2011). ¿Qué pasa con la Vicepresidencia?. Portafolio. Recuperado el 15 de abril de 2012, de la fuente: http://www.portafolio.co/columnistas/\%25C2\%25BFque-pasa-la-vicepresidencia

GÓMEZ, Laureano. (2001). El Control Constitucional en Colombia. Evolución Histórica. Bucaramanga (Colombia): UNAB.

GOLDSTEIN, Joel. (2000). ¿Can the Vice President Preside at His Own Impeachment Trial?: A critique of bare textualism. Unites States: Saint Louis University scholl of law. From GARVEY, Todd. A Constitutional Anomaly: Safeguarding Confidential National Security Information Within the Enigma That Is the American Vice Presidency. 17 Wm. \& Mary Bill of Rts. J. 565. Recuperado el 13 de febrero, de la fuente: http://scholarship.law.wm.edu/wmborj/vol17/iss2/11

HENAO, Javier. (1996). Panorama del Derecho Constitucional Colombiano. Santa Fe de Bogotá: Temis S.A.

HENAO, H. Javier. 2011. Constitución Política de Colombia 1991. Bogotá D.C.: Temis.

HERRERA, Wilson. 2004. La Rama Ejecutiva del Poder Público. BarranquillaColombia: Universidad del Norte. Revista de Derecho, 21. 
MUÑOZ M., PAULA XIMENA (2014): “RESPONSABILIDAD DEL VICEPRESIDENTE DE LA REPÚBLICA EN EJERCICIO DE SUS FUNCIONES CONSTITUCIONALES”, VIA INVENIENDI ET IUDICANDI, Vol. 9, No. 1, pp.

HIDRÓN H, Javier. (2011). Constitución Política de Colombia (Comentada). Bogotá: Temis S.A.

IVANEGA, Miriam. (2007). Estudios sobre la responsabilidad del Estado en Argentina, Colombia y México. Instituto de Investigaciones Jurídicas. México D.F.: Universidad Nacional Autónoma de México.

JARAMILLO P., Daniel. (1993). ¿Qué nos significa la vicepresidencia?: Cómo se gestó en la Constituyente y qué puede esperarse del Vicepresidente. Revista Credencial Historia. Vol. (39). Recuperado el día 6 de julio de 2012, de la fuente: http://www.banrepcultural.org/blaavirtual/revistas/credencial/marzo1993/marzo1.htm

JELLINEK, G. (2009). Sistema dei Diritti Publici. Milano, società Editrice Libraria. 1912.p 197 y ss. Tomado de Rincón Córdoba, Jorge I. Derecho Administrativo Laboral. Empleo público, sistema de carrera administrativa y derecho a la estabilidad laboral. Bogotá D.C: Universidad Externado de Colombia.

JIMÉNEZ, Manuel. (1974). Los Regímenes Políticos Contemporáneos. Teoría general del Régimen. Las grandes democracias con tradición democrática. Madrid: Tecnos.

KELSEN, Hans. (1949). Teoría General del Derecho y del Estado. México D.F.: Universidad Nacional Autónoma de México.

LASARTE, Carlos (2005). Compendio de Derecho Civil. Trabajo Social y Relaciones Laborales. Madrid: Dykinson.

LICONA, Cecilia. (2007). Juicio Político. México: Centro de Estudios de derecho e investigaciones parlamentarias.

LLERAS, C \& TANGARIFE, M. (1996). Constitución Política de Colombia: Origen, Evolución y Vigencia. Bogotá D.C.: Biblioteca Jurídica Diké.

LLANOS, Wilson. (2004). La Rama Ejecutiva del Poder Público. Revista de Derecho: Universidad del Norte. Vol (21). Recuperado el día 19 de mayo de 2012, de la fuente http://ciruelo.uninorte.edu.co/pdf/derecho/21/12 LA\%20RAMA\%20EJECUTIVA\%20 DEL\%20PODER\%20PUBLICO DERECHO No\%2021.pdf

ORTIZ, Luis. (2005). La Vicepresidencia en Colombia. Historia de una institución cuestionada. Bogotá: Base de datos de la Biblioteca del Banco de la República. 2005.

PÉREZ, Martín. (1994). Mandato y representación en el derecho histórico. Anales de Derecho, Universidad de Maurcia, No. 12 (p. 205 - 264, recuperado el 2 de febrero de 2013: http://www.google.com.co/url? sa=t\&rct=i\&q=\&esrc=s\&frm=1\&source=web\&cd=1\&ve

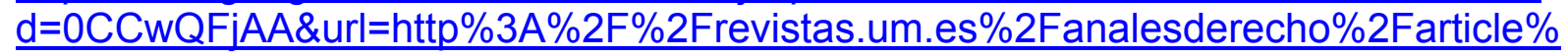
2Fview\%2F82251\%2F79321\&ei=DHINUe- 
MUÑOZ M., PAULA XIMENA (2014): “RESPONSABILIDAD DEL VICEPRESIDENTE DE LA REPÚBLICA EN EJERCICIO DE SUS FUNCIONES CONSTITUCIONALES”, VIA INVENIENDI ET IUDICANDI, Vol. 9, No. 1, pp.

HG5GE8QSM44DoCA\&usg=AFQjCNF3RJF4-

BnpphHw0G542uGRkH9hbA\&bvm=bv.41867550,d.eWU

PENAGOS, Gustavo. (2004). Derecho Administrativo Nuevas Tendencias. Tomo II. Bogotá D.C: Ediciones Doctrina y Ley.

PRITCHETT, Herman. (1965). La Constitución Americana. Argentina: Tipografía Argentina S.A.

RESTREPO, Carlos. (1995). Constituciones Políticas Nacionales de Colombia. Bogotá: Universidad Externado de Colombia.

REBOLLO, Luis. (2001). Los fundamentos de la responsabilidad del Estado, en AA VV, Responsabilidad del Estado y de los funcionarios públicos. (pp., 1-38) jornadas organizadas por la Universidad Austral, Facultad de Derecho. Buenos Aires.

VIDAL J; BRITO R, Y OTROS. (2006). Teoría de la organización administrativa colombiana. Una visión jurídico - administrativa. Bogotá D.C.: Centro Editorial Universidad del Rosario. Escuela Superior de Administración Pública ESAP.

\section{Sentencias Consejo de Estado:}

Consejo de Estado. Consejero ponente: Alfonso Arango Henao. 27 de septiembre de 1974.

Consejo de Estado. Consejero ponente: Manuel Santiago Urueta; 14 de julio de 1998.

Consejo de Estado. Consejero ponente: Germán Rodríguez Villamizar; 5 de agosto de 1999.

\section{Sentencias Corte Constitucional}

Corte Constitucional. Sentencia C-522. Magistrado ponente Dr. Fabio Morón Díaz; 16 de noviembre de 1994.

Corte Constitucional. Sentencia C-594. Magistrado ponente Antonio Barrera Carbonell; 7 de diciembre de 1995.

Corte Constitucional. Sentencia C-484. Magistrado ponente Fabio Morón Díaz; 30 de octubre de 1995.

Constitucional. Sentencia C-369. Magistrado ponente Fabio Morón Díaz; 26 de mayo de 1999.

Corte Constitucional. Sentencia C-561 del 4 de agosto de 1999. Expediente D-2376. M.P. Alfredo Beltrán Sierra. 
MUÑOZ M., PAULA XIMENA (2014): “RESPONSABILIDAD DEL VICEPRESIDENTE DE LA REPÚBLICA EN EJERCICIO DE SUS FUNCIONES CONSTITUCIONALES”, VIA INVENIENDI ET IUDICANDI, Vol. 9, No. 1, pp.

Corte Constitucional. Sentencia C-382 del 5 de abril de 2000. Expedientes D-3770 y D-3775 M.P. Antonio Barrera Carbonell.

Corte Constitucional. Sentencia C-727. Magistrado ponente Vladimiro Naranjo Mesa; 21 de junio de 2000.

Corte Constitucional. Sentencia C-802 del 27 de septiembre de 2006. Expediente D615B. M.P. Dr. Manuel José Cepeda Espinosa. 